\title{
Biodiversity-productivity relationships are key to nature-based climate solutions
}

Akira S Mori ${ }^{1 *}$, Laura E Dee ${ }^{2}$, Andrew Gonzalez ${ }^{3}$, Haruka Ohashi ${ }^{4}$, Jane Cowles ${ }^{5}$, Alexandra J Wright $^{6}$, Michel Loreau ${ }^{7}$, Yann Hautier ${ }^{8}$, Tim Newbold ${ }^{9}$, Peter B Reich ${ }^{10,11}$, Tetsuya Matsui ${ }^{12}$, Wataru Takeuchi $^{13}$, Kei-ichi Okada ${ }^{1,14}$, Rupert Seidl ${ }^{15,16}$, Forest Isbell ${ }^{4}$

${ }^{1}$ Faculty of Environment and Information Sciences, Yokohama National University, 79-7 Tokiwadai, Hodogaya, Yokohama, Kanagawa, 240-8501, Japan; ${ }^{2}$ Department of Ecology and Evolutionary Biology, University of Colorado, Boulder, Colorado, 80309, USA; ${ }^{3}$ Department of Biology, Quebec Centre for Biodiversity Science, McGill University, 1205 Dr. Penfield Avenue, Montreal, Quebec, H3A 1B1, Canada; ${ }^{4}$ Department of Wildlife Biology, Forestry and Forest Products Research Institute, Forest Research and Management Organization, 1 Matsunosato, Tsukuba, Ibaraki, 305-8687, Japan; ${ }^{5}$ Department of Ecology, Evolution and Behavior, University of Minnesota, St Paul, Minnesota, 55108, USA; ${ }^{6}$ California State University Los Angeles, 5151 State University Dr., Los Angeles, California, 90032, USA; ${ }^{7}$ Theoretical and Experimental Ecology Station, CNRS, 09200, Moulis, France; ${ }^{8}$ Ecology and Biodiversity Group, Department of Biology, Utrecht University, Padualaan 8, $3584 \mathrm{CH}$ Utrecht, Netherlands; ${ }^{9}$ Centre for Biodiversity and Environment Research, Department of Genetics, Evolution and Environment, University College London, Gower Street, London WC1E 6BT, UK; ${ }^{10}$ Department of Forest Resources, University of Minnesota, St Paul, Minnesota, 55108, USA; ${ }^{11}$ Hawkesbury Institute for the Environment, Western Sydney University, Penrith, New South Wales, 2753, Australia; ${ }^{12}$ Center for International Partnerships and Research on Climate Change, Forestry and Forest Products Research Institute, Forest Research and Management Organization, 1 Matsunosato, Tsukuba, Ibaraki, 305-8687, Japan; ${ }^{13}$ Institute of Industrial Science, The University of Tokyo, 4-6-1 Komaba, Meguro, Tokyo 153-8505, Japan; ${ }^{14}$ Faculty of Bioindustry, Tokyo University of Agriculture, 196 Yasaka, Abashiri, Hokkaido, 099-2493, Japan; ${ }^{15}$ School of Life Sciences, Technical University of Munich, Hans-Carl-von-Carlowitz-Platz 2, 85354 Freising, Germany; ${ }^{16}$ Berchtesgaden National Park, Doktorberg 6, 83471, Berchtesgaden, Germany

*Corresponding author: akira.s.mori@gmail.com / akkym@ynu.ac.jp 
The global impacts of biodiversity loss and climate change are interlinked but the feedbacks between them are rarely assessed. Areas with greater tree diversity tend to be more productive, providing a greater carbon sink, and biodiversity loss could reduce these natural $\mathrm{C}$ sinks. Here, we quantify how tree and shrub species richness could affect biomass production at biome, national and regional scales. We find that greenhouse gas mitigation could help maintain tree diversity and thereby avoid a 9-39\% reduction in terrestrial primary productivity across differ biomes, which cold otherwise occur over the next 50 years. Countries that will incur the greatest economic damages from climate change stand to benefit the most from conservation of tree diversity and primary productivity, which contributes to climate change mitigation. Our results emphasize an opportunity for a triple win for climate, biodiversity and society, and highlight how these co-benefits must be focused by reforestation programs.

Climate change and biodiversity loss are two major environmental challenges in this era of global change ${ }^{1}$. Although the tight linkages between them have been recognized ${ }^{2,3}$, the vast majority of attention has been paid to one unidirectional relationship — climate change as a cause and biodiversity loss as a consequence. Climate change is projected to become an increasingly important driver of biodiversity loss ${ }^{4,5}$ and its interaction with other major drivers such as land-use change will indirectly accelerate its impacts on biodiversity ${ }^{6}$ further. For example, in terrestrial systems, the majority of species ranges are predicted to shrink dramatically, even for a rise in global temperature below $2^{\circ} \mathrm{C}^{4,7}$. Besides, some land-based measures of climate change mitigation have detrimental side-effects on ecosystems ${ }^{4,8}$, because of substantial land conversions such as large-scale bioenergy crop production and afforestation with monocultures ${ }^{9}$. There is now recognition of the need for nature-based solutions, which involve working with nature to address societal challenges such as climate change ${ }^{10-13}$. Better management and restoration of natural ecosystems, such as forests, coastal lands, and peatlands, could produce multiple benefits to society including the conservation of biodiversity and sequestration of carbon $^{2,3,10-15}$. In response, the United Nations (UN) has declared the present decade (2021-2030) as the Decade on Ecosystem Restoration (www.decadeonrestoration.org) to ensure ecosystem services are sustained, such as the removal of carbon from the atmosphere. However, natural climate solutions are currently missing biodiversity as part of the equation: that is, although biodiversity is often seen as a target for conservation, it is not yet widely appreciated as a powerful contributor to climate stabilization $^{11,13,16}$.

Forest productivity is often higher in species-rich forests, consequently absorbing more carbon than species-poor forests such as tree monocultures ${ }^{17-19}$. Moreover, communities with more species are better able to sustain their productivity in the face of global environmental change, indicating a synergistic interaction between biodiversity and climate change ${ }^{16}$. Thus, conserving biodiversity, and particularly the diversity of tree species may have a previously unquantified contribution to global climate change mitigation ${ }^{13}$. Biodiversity loss is increasingly recognized as a 
driver that can amplify climate risks and the associated economic risks ${ }^{20}$. However, it is still challenging to quantitatively incorporate the effects of diversity change on carbon storage - which often arise from local-scale species interactions ${ }^{21}$ — into global-scale models ${ }^{22,23}$ that assess how landuse changes and vegetation dynamics will drive future climate change ${ }^{24}$. Here, we assess how biodiversity effects on climate change - the ecological and marginal economic benefits of having more species in an ecosystem - might accumulate at larger scales relevant to policy ${ }^{8,25}$.

We assess how efforts to mitigate climate change can reduce climate impacts on the diversity of woody plant species (hereafter, tree diversity) which, in turn, can safeguard the ability of forests to store carbon (Fig. 1). To assess this potential at the global scale, we quantified future shifts in species richness at the local scale (i.e., 30 arcseconds, the total number of grids $\sim 115$ million; Fig. 2) by combining multiple methods of ecological modelling (See Methods for the details). We combined these local-scale estimates of species richness changes with local-scale estimates of proportional changes in primary productivity in response to richness changes ${ }^{17}$ - a parameter estimated within forests, which reflects the strength of local tree diversity effects on productivity after accounting for climate and soil covariates. Then, by further multiplying these estimates by net primary productivity (NPP; Pg C year ${ }^{-1}$ ) derived from MODIS (Moderate Resolution Imaging Spectroradiometer) imagery $^{26}$, we quantified how proportional changes in local species richness could affect changes in biomass production (i.e., tree diversity-dependent productivity) at the local scale. Finally, we aggregated these changes in local productivity to produce large-scale estimates of changes in productivity (due to changes in tree diversity resulting from climate change) at biome, national, and regional scales (Figs. 3-5). Note that, among many primary producer species, we especially focused on tree and shrub species (hereafter jointly referred to as trees) in different biomes. As some of them are present also in non-forested biomes, our global analyses extend to woody species in all terrestrial biomes (all 14 biomes defined by the World Wildlife Fund: www.worldwildlife.org/biomes). At a regional scale, we focused on the subregion categories of the Intergovernmental Science-Policy Platform on Biodiversity and Ecosystem Services (IPBES: ipbes.net/regional-assessments) ${ }^{7}$.

Our analyses used five shared socioeconomic pathways (SSPs) reflecting different plausible projections of land-use change ${ }^{27}$. The underlying allocation scheme, based on an integrated assessment model, implements climate change mitigation in the form of a globally uniform carbon tax on greenhouse gas emissions from the agriculture, land-use, and energy sectors ${ }^{27}$. Using a scenario matrix architecture, we compared two future scenarios: high-emission baseline versus mitigation scenario $^{28}$. The mitigation scenario assumes levels of greenhouse gas emissions will stabilize the global mean temperature rise relative to preindustrial times to less than $2{ }^{\circ} \mathrm{C}$ by the end of the $21^{\text {st }}$ century. The baseline scenario assumes a continued increase in greenhouse gas emissions, and thus also the global mean surface temperature continues to rise. We relied on three General Circulation Models (GCMs) to consider two different representative concentration pathways (RCPs) in each of the five $\mathrm{SSPs}^{27}$. Thus, we considered a wide range of future land allocation and climate conditions ${ }^{28}$. 
We quantified how efforts to mitigate climate change could alleviate species loss $(\Delta \mathrm{SR})$ and thereby avoid biodiversity-dependent productivity loss $(\Delta \mathrm{P})$ at the local-scale as log ratios, with zero corresponding to the true absence of the effect (see Methods for the details).

We found that, in many biomes, climate change mitigation could substantially reduce the global loss of tree diversity that would otherwise be expected to result from an unabated continuation of climate change (Fig. 2). This, in turn, is expected to reduce the loss of productivity that would otherwise be expected to result from biodiversity loss (Fig. 3). Climate change mitigation is estimated to curtail productivity losses by approximately $9-39 \%$ compared to the baseline scenario of unabated warming (Fig. 3). The alleviated loss of tree diversity and the resultant conservation of biodiversitydependent productivity are especially substantial in colder and drier biomes compared to warmer and wetter biomes, likely because species in these biomes are often close to the edge of their climatic niche $^{29}$. Losing one species may have a disproportionate impact in ecosystems where only a limited number of species are filling niche space and functional redundancy is thus low. Among these biomes, particularly colder areas are expected to gain species in a warmer future, due to the poleward migration of species. However, the poor dispersal ability of trees (coupled with the pace of climate change and land-use change) generally makes it difficult for species to track their environmental optimum under anthropogenic warming ${ }^{28,30}$. Further, warming could alter the strength of the diversity-productivity relationship, though this has not yet been well-studied in forests. A possibility is that, if conditions become less limiting due to climatic warming, the productivity of individual trees might increase, potentially offsetting the negative impacts of species decline on primary productivity. Due to these and other possibilities, responses of tree diversity and the associated productivity in a changing climate can vary by region ${ }^{31}$. Variable responses among biomes are also seen for the absolute impacts of losing diversity in different biomes of the world. While the per-area loss of biodiversity-dependent productivity tended to be small in warmer biomes such as tropical and subtropical forests, their gross contribution to global productivity loss was considerable due to their high absolute productivity and the extent of these biomes (Fig. 4). The analysis conducted at the IPBES subregional scale also illustrates the spatially heterogeneous effectiveness of climate change mitigation efforts in safeguarding forest productivity (Fig. 5). This heterogeneity in the responses among regions is partly due to variation in the extent to which biodiversity is conserved when climate change is mitigated (Fig. 2; Extended Data Figs. 1-3). Furthermore, substantial land-use changes may be required for stringent mitigation efforts, especially under the scenarios of high demand for bioenergy consumption ${ }^{32}$, which could have detrimental effects on biodiversity in some regions $s^{4,28}$. Overall, although the estimations were variable among GCMs and SSPs (Extended Data Figs. 1-7), tree diversity in most biomes and subregions would benefit from additional efforts to reduce greenhouse gas emissions. Overall, climate change mitigation efforts conserve the diversity of woody plant species and primary productivity, which contributes to carbon storage in terrestrial ecosystems.

To gain further insights at the national level, the scale at which many policy decisions are 
made, we aggregated the regional heterogeneity into country-level estimates and considered how tree diversity effects on productivity at the country-level relate to the economic value of avoiding carbon emissions. Here, we obtained the absolute country-wide estimate of reductions in productivity loss due to climate mitigation efforts. We compared these estimates with the country-level social cost of carbon ( $\mathrm{CSCC}$; $\mathrm{US} \$ \mathrm{tCO}_{2}{ }^{-1}$ ), which is the marginal damage expected to occur in a particular country as a consequence of additional $\mathrm{CO}_{2}$ emissions produced anywhere in the world ${ }^{33}$. We found that countries with a high country-level social cost of carbon, which have the greatest incentive to mitigate climate change to avoid its economic damages, also tend to be the countries where climate change mitigation could greatly help maintain primary productivity by safeguarding tree diversity, regardless of model and scenario (Fig. 6a; Extended Data Fig. 8). Thus, countries with both large CSCC and productivity conservation potential, which especially include but are not limited to those with a large land area (Fig. 6b-c; Extended Data Fig. 9), have a great incentive to focus their efforts on stabilizing climate by safeguarding tree diversity as a potent nature-based climate solution ${ }^{10}$, in addition to reducing the emissions from industry and the energy sector ${ }^{34}$. For instance, the US and China-the two biggest emitters of carbon - are estimated to experience some of the biggest economic damages due to anthropogenic global warming ${ }^{33}$, indicating a great responsibility and opportunity to mitigate emissions by maintaining tree diversity. Brazil has the largest potential to benefit in multiple ways from climate mitigation efforts (outliers in Fig. 6a; also see Extended Data Fig. 9). In contrast, Canada and Russia are expected to experience only small economic damages or may even benefit from climatic warming ${ }^{33}$. Nonetheless, as the largest forested countries in the world, their contributions are a vital part in considering biodiversity-dependent productivity as a nature-based solution, particularly since they also have experienced the largest loss of tree cover in recent years ${ }^{35}$. Moreover, India and Indonesia - which bear some of the greatest social costs of carbon pollution even though they are not among the top emitters of carbon ${ }^{33}$ - have pledged to restore large areas of natural forests ${ }^{14}$. Such efforts offer opportunities for the international community to internalize the global climate externality and help achieve global pathways to stabilize climate while also conserving biodiversity. Although restoring natural forests and their biodiversity will not fully compensate for greenhouse gas emissions, this strategy could be developed to form clear national and international targets ${ }^{13}$.

We estimate that the possible conservation of biodiversity-dependent annual productivity by means of climate change mitigation corresponds to approximately $4.9-6.7 \%$ of the present total NPP in the terrestrial areas analysed (Fig. 6d). This substantial contribution emphasizes that biodiversity conservation is not only a target in and of itself but can also be a significant part of the solution to the ongoing climate crisis. Our results indicate that ambitious efforts to mitigate climate change - at both the national and global levels - have a significant potential to help societies reduce the externalized cost of carbon. Although decarbonizing the economy and relying on nature for carbon storage are both seen as important but parallel options ${ }^{34}$, our results quantitatively show that they are tightly connected. Still, many reforestation programs and policies focus on monocultures ${ }^{11,14}$, which misses 
the potential contribution of tree diversity to carbon sequestration we highlight here. We stress the value of restoring and conserving diverse natural forests, which harbour great plant, animal, and microbial biodiversity, provide a variety of ecosystem services ${ }^{36}$, and contribute to climate stabilization ${ }^{11,14}$. Carbon-based forest management has been suggested as a way forward ${ }^{37}$, but an estimated $45 \%$ of national-level commitments to restore forests propose monocultures of trees profitable for businesses ${ }^{14}$. Planting vast expanses of monocultures will preclude the opportunity for a triple win for nature, climate, and society that can arise by fostering tree biodiversity (Fig. 1).

Sustainable forest management has been emphasized in many policy contexts ${ }^{38}$, including $\mathrm{UN}$ frameworks ${ }^{39-41}$ and can provide a natural climate solution pathway ${ }^{10}$. While sustainable forest management emphasizes the importance of biodiversity conservation as an objective $e^{3,36}$, climate policy has, to date, largely ignored the dependence of primary productivity on biodiversity and the contribution of tree diversity to carbon storage $\mathrm{e}^{16,19,31}$. Despite this gap, reports produced by the UN Convention on Biological Diversity have repeatedly supported the use of biodiversity and ecosystem services as part of an overall strategy to help mitigate climate change and the associated risks to society ${ }^{41,42}$. Since 2009 , this UN framework has mentioned the potential of increasing biodiversity in forests, emphasizing the positive effects on ecosystem productivity and carbon storage ${ }^{41}$. Yet most strategies to date have focused on avoiding further land conversion and expanding forested areas ${ }^{14}$. In addition to considering the spatial extent of forests, the status and quality of forests - e.g., in an extreme comparison, whether they are mono-species plantation or species-diverse old-growth stands - deserves further consideration ${ }^{11,13,14,16}$. A dual focus on both the quantity (area) and the quality (biodiversity) of forest ecosystems could help support climate stabilization. We therefore emphasize the great value of biologically diverse forests ${ }^{16,17,19,36}$, both planted and restored.

The projections we make contain several sources of uncertainty, which future research could help resolve. For example, we focus on a limited subset of woody species to represent the tree diversity in the forests around the globe (Extended Data Fig. 10). Most species on Earth are still poorly described, which makes estimating their present and future ranges challenging ${ }^{5}$. Our estimates are thus likely conservative because they are based on well-documented species, whereas poorly described species, which often have narrow geographical ranges and small population sizes, are more prone to climate-driven extinction ${ }^{43}$. Given the disproportionately large contributions by some rare species to ecosystem functioning ${ }^{44}$, our approximation of biodiversity-dependent productivity could be seen as a lower bound estimate. While modelling the spatial distributions of rare species, which generally have a limited number of occurrence data, is challenging, analytical approaches are developing rapidly to foster the conservation of poorly described species ${ }^{45}$. These emerging methods will help to improve future estimates of biodiversity change and its consequences for the supply of ecosystem services.

Another source of uncertainty is that new combinations of species are likely to emerge under a changing climate ${ }^{3}$, which may alter interactions between species ${ }^{29}$ and likely influence the 
magnitude of diversity-productivity relationships ${ }^{31}$. Although the dispersal ability of each tree species is explicitly considered in our analysis, it is highly likely that novel combinations of species will emerge in the future, resulting from idiosyncratic events (e.g., exceptional long-distance dispersal ${ }^{46}$ ) and human influences (e.g., climate-suitable planting and assisted migration ${ }^{12,31}$ ). Furthermore, our results should be interpreted with care because responses at the biome level were not necessarily consistent across socioeconomic pathways (Fig. 3). This was especially true when summarized at large scales such as at the level of IPBES $^{7}$ subregions (Fig. 5): Large variability was especially identified in Western/Central Asian and West African subregions, where the outcomes of climate change mitigation policy ranged from negative to positive. In this study, we did not separate the individual influences of different climate mitigation practices (e.g., reforestation, bioenergy production, and low-carbon energy use) on biodiversity and primary productivity, but doing so could help identify drivers underlying such inconsistent responses in the future. For example, if mitigation goals were achieved by afforestation in formerly non-forested lands such as peatlands and grasslands, then this could have unintended negative impacts on biodiversity and the productivity of these ecosystems ${ }^{47}$. Another consideration is that the ability of forests to increase the uptake of carbon in the short-term (e.g., over the next decade) cannot be linearly translated into the ability of forests to halt climate warming over a 50-100 year time horizon. This is because complex biogeochemical and biophysical processes - for instance, surface exchange of energy and water vapor and sensible heat flux, resulting from compositional and structural changes in forests - might not directly parallel the effects of carbon uptake rates on climate ${ }^{48,49}$. Carbon storage in deadwood and soil—significant drivers of terrestrial carbon dynamics ${ }^{19,50}$ — was also not considered in this study. Finally, in our estimates of the change in social cost from conserving species and productivity (Fig. 6), we did not fully account for management and opportunity costs. Nonetheless, our estimates provide a first global assessment of the contribution of biodiversity in forests to climate change mitigation on which future refinements can build upon.

We advocate for the protection and restoration of biologically diverse forests, because they can make a substantial contribution to climate change mitigation ${ }^{16,19}$, helping to avoid irreversible change to the Earth system ${ }^{1}$. Nature-based solutions are among the fastest ${ }^{2}$ and most cost-effective policy options ${ }^{10,11}$. As such, there is an enthusiasms for relying on trees and forests to recapture carbon $^{37}$. Now, it is urgently necessary to accurately assess this potential to guide the ongoing efforts such as the Intergovernmental Panel on Climate Change ${ }^{51}$. Here we identify an important backbone for these considerations - tree diversity - as an missing piece of the nature-based climate solution puzzle. By buying time ${ }^{4}$, climate mitigation efforts are essential to help both people and biodiversity adapt to climate change ${ }^{12}$. Our emphasis on biodiversity-dependent climate change mitigation is thus also important for ecosystem-based adaptation ${ }^{3}$. However, a nature-based approach is only one option $^{15,52}$ along with others that are necessary, including substantial reductions in energy emissions and the transition to renewable sources of energy ${ }^{34}$. Although challenging, reducing the adverse 
impacts of climate change on species in ecosystems is important (Fig. 2) as they serve as a massive sink and storehouse of carbon (Figs. 3-5), thereby contributing to climate stabilization (the desirable pathway to stabilizing feedback between climate change mitigation and biodiversity conservation in Fig. 1). Solving one environmental problem may help address the other, whereas failing to address either problem may lead to the further deterioration of both biodiversity and climate crises. Here we show an opportunity to create a triple win for climate, nature, and society by simultaneously protecting and leveraging the ecosystem benefits contributed by the biodiversity of the world's forests.

\section{REFERENCES}

1 UN Environment. Global Environment Outlook - GEO6: Healthy Planet, Healthy poeple. (Nairobi, 2019).

2 Dinerstein, E. et al. A Global Deal For Nature: Guiding principles, milestones, and targets. Sci Adv 5, eaaw2869, doi:10.1126/sciadv.aaw2869 (2019).

3 Mori, A. S., Spies, T. A., Sudmeier-Rieux, K. \& Andrade, A. Reframing ecosystem management in the era of climate change: Issues and knowledge from forests. Biol Conserv 165, 115-127, doi:DOI 10.1016/j.biocon.2013.05.020 (2013).

4 Warren, R., Price, J., Graham, E., Forstenhaeusler, N. \& VanDerWal, J. The projected effect on insects, vertebrates, and plants of limiting global warming to 1.5 degrees $\mathrm{C}$ rather than 2 degrees C. Science 360, 791-795, doi:10.1126/science.aar3646 (2018).

5 Garcia, R. A., Cabeza, M., Rahbek, C. \& Araujo, M. B. Multiple dimensions of climate change and their implications for biodiversity. Science 344, 1247579, doi:10.1126/science.1247579 (2014).

6 Urban, M. C. Climate change. Accelerating extinction risk from climate change. Science 348, 571-573, doi:10.1126/science.aaa4984 (2015).

7 IPBES. Summary for policymakers of the global assessment report on biodiversity and ecosystem services of the Intergovernmental Science-Policy Platform on Biodiversity and Ecosystem Services. (2019).

8 Midgley, G. F. et al. Terrestrial carbon stocks and biodiversity: key knowledge gaps and some policy implications. Current Opinion in Environmental Sustainability 2, 264-270, doi:10.1016/j.cosust.2010.06.001 (2010).

9 Jones, A. D., Calvin, K. V., Collins, W. D. \& Edmonds, J. Accounting for radiative forcing from albedo change in future global land-use scenarios. Climatic Change 131, 691-703, doi:10.1007/s10584-015-1411-5 (2015).

10 Griscom, B. W. et al. Natural climate solutions. Proc Natl Acad Sci U S A 114, 11645-11650, doi:10.1073/pnas.1710465114 (2017).

11 Seddon, N., Turner, B., Berry, P., Chausson, A. \& Girardin, C. A. J. Grounding nature-based climate solutions in sound biodiversity science. Nat Clim Change 9, 84-87, 
doi:10.1038/s41558-019-0405-0 (2019).

12 Morecroft, M. D. et al. Measuring the success of climate change adaptation and mitigation in terrestrial ecosystems. Science 366, doi:10.1126/science.aaw9256 (2019).

13 Mori, A. S. Advancing nature-based approaches to address the biodiversity and climate emergency. Ecol Lett, doi:10.1111/ele.13594 (2020).

14 Lewis, S. L., Wheeler, C. E., Mitchard, E. T. A. \& Koch, A. Restoring natural forests is the best way to remove atmospheric carbon. Nature 568, 25-28, doi:10.1038/d41586-019-010268 (2019).

15 Holl, K. D. \& Brancalion, P. H. S. Tree planting is not a simple solution. Science 368, 580581, doi:10.1126/science.aba8232 (2020).

16 Hisano, M., Searle, E. B. \& Chen, H. Y. H. Biodiversity as a solution to mitigate climate change impacts on the functioning of forest ecosystems. Biol Rev 93, 439-456, doi:10.1111/brv.12351 (2018).

17 Liang, J. et al. Positive biodiversity-productivity relationship predominant in global forests. Science 354, doi:10.1126/science.aaf8957 (2016).

18 Mori, A. S. Environmental controls on the causes and functional consequences of tree species diversity. $J$ Ecol 106, 113-125, doi:10.1111/1365-2745.12851 (2018).

19 Hulvey, K. B. et al. Benefits of tree mixes in carbon plantings. Nat Clim Change 3, 869-874, doi:10.1038/nclimate1862 (2013).

20 World Economic Forum. The Global Risks Report 2020. (World Economic Forum, Geneva, Switzerland, 2020).

21 Tilman, D., Isbell, F. \& Cowles, J. M. Biodiversity and ecosystem functioning. Ann Rev Ecol Evol Syst 45, 471-493, doi:10.1146/annurev-ecolsys-120213-091917 (2014).

22 Isbell, F., Tilman, D., Polasky, S. \& Loreau, M. The biodiversity-dependent ecosystem service debt. Ecol Lett 18, 119-134, doi:10.1111/ele.12393 (2015).

23 Gonzalez, A. et al. Scaling-up biodiversity-ecosystem functioning research. Ecol Lett 23, 757776, doi:10.1111/ele.13456 (2020).

24 Mokany, K. et al. Integrating modelling of biodiversity composition and ecosystem function. Oikos 125, 10-19, doi:10.1111/oik.02792 (2016).

25 Isbell, F. et al. Linking the influence and dependence of people on biodiversity across scales. Nature 546, 65-72, doi:10.1038/nature22899 (2017).

26 Running, S., Mu, Q., Zhao, M. \& MODAPS-SIPS. (NASA, 2015).

27 Fujimori, S., Hasegawa, T., Ito, A., Takahashi, K. \& Masui, T. Gridded emissions and landuse data for 2005-2100 under diverse socioeconomic and climate mitigation scenarios. Scientific Data 5, 180210, doi:10.1038/sdata.2018.210 (2018).

28 Ohashi, H. et al. Biodiversity can benefit from climate stabilization despite adverse side effects of land-based mitigation. Nat Commun 10, 5240, doi:10.1038/s41467-019-13241-y 
(2019).

29 Bellard, C., Bertelsmeier, C., Leadley, P., Thuiller, W. \& Courchamp, F. Impacts of climate change on the future of biodiversity. Ecol Lett, doi:10.1111/j.1461-0248.2011.01736.x (2012).

30 Fadrique, B. et al. Widespread but heterogeneous responses of Andean forests to climate change. Nature 564, 207-212, doi:10.1038/s41586-018-0715-9 (2018).

31 Ammer, C. Diversity and forest productivity in a changing climate. New Phytologist 221, 5066, doi:10.1111/nph.15263 (2019).

32 Hasegawa, T. et al. Risk of increased food insecurity under stringent global climate change mitigation policy. Nat Clim Change 8, 699-703, doi:10.1038/s41558-018-0230-x (2018).

33 Ricke, K., Drouet, L., Caldeira, K. \& Tavoni, M. Country-level social cost of carbon. Nat Clim Change 8, 895-900, doi:10.1038/s41558-018-0282-y (2018).

34 Anderson, C. M. et al. Natural climate solutions are not enough. Science 363, 933-934, doi:10.1126/science.aaw2741 (2019).

35 Potapov, P. et al. The last frontiers of wilderness: Tracking loss of intact forest landscapes from 2000 to 2013. Sci Adv 3, e1600821, doi:10.1126/sciadv.1600821 (2017).

36 Mori, A. S., Lertzman, K. P. \& Gustafsson, L. Biodiversity and ecosystem services in forest ecosystems: a research agenda for applied forest ecology. J Appl Ecol 54, 12-27, doi:10.1111/1365-2664.12669 (2017).

37 Bastin, J. F. et al. The global tree restoration potential. Science 365, 76-79, doi:10.1126/science.aax0848 (2019).

38 Quine, C. P., Bailey, S. A., Watts, K. \& Hulme, P. Sustainable forest management in a time of ecosystem services frameworks: common ground and consequences. J Appl Ecol 50, 863-867, doi:10.1111/1365-2664.12068 (2013).

39 FAO. Climate change for forest policy-makers. An approach for integrating climate change into national forest policy in support of sustainable forest management Version 2.0. (Food and Agriculture Organization of the United Nations, Rome, Italy, 2018).

40 UNDP. Biodiversity and ecosystems global framework 2012 to 2020. 69 (United Nations Development Programme, New York, USA, 2012).

41 CBD. Forest resilience, biodiversity, and climate change - A synthesis of the biodiversity/resilience/stability relationship in forest ecosystems. 67 (Convention on Biological Diversity, Montreal, Canada, 2009).

42 CBD. Connecting biodiversity and climate change mitigation and adaptation: Report of the second ad hoc technical expert group on biodiversity and climate change 126 (Convention on Biological Diversity, Montreal, Canada, 2009).

43 Pimm, S. L. et al. The biodiversity of species and their rates of extinction, distribution, and protection. Science 344, 1246752, doi:10.1126/science.1246752 (2014).

44 Dee, L. E. et al. When Do Ecosystem Services Depend on Rare Species? Trends Ecol Evol 
34, 746-758, doi:10.1016/j.tree.2019.03.010 (2019).

45 Fois, M., Cuena-Lombraña, A., Fenu, G. \& Bacchetta, G. Using species distribution models at local scale to guide the search of poorly known species: Review, methodological issues and future directions. Ecol Model 385, 124-132, doi:10.1016/j.ecolmodel.2018.07.018 (2018).

46 Jordano, P. \& Rees, M. What is long-distance dispersal? And a taxonomy of dispersal events. J Ecol 105, 75-84, doi:10.1111/1365-2745.12690 (2017).

47 Veldman, J. W. et al. Comment on "The global tree restoration potential". Science 366, doi:10.1126/science.aay7976 (2019).

48 Naudts, K. et al. Europe's forest management did not mitigate climate warming. Science 351, 597-600, doi:10.1126/science.aad7270 (2016).

49 Luyssaert, S. et al. Trade-offs in using European forests to meet climate objectives. Nature 562, 259-262, doi:10.1038/s41586-018-0577-1 (2018).

50 Crowther, T. W. et al. Quantifying global soil carbon losses in response to warming. Nature 540, 104-108, doi:10.1038/nature20150 (2016).

51 Cook-Patton, S. C. et al. Mapping carbon accumulation potential from global natural forest regrowth. Nature 585, 545-550, doi:10.1038/s41586-020-2686-x (2020).

52 Bellamy, R. \& Osaka, S. Unnatural climate solutions? Nat Clim Change 10, 98-99, doi:10.1038/s41558-019-0661-z (2020). 

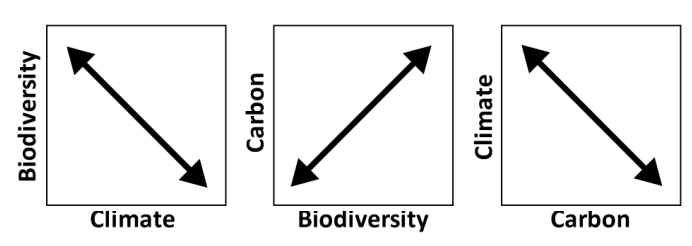

Climate:

The magnitude of anthropogenic climate change

Biodiversity:

Diversity of organisms such as woody plant species

Carbon:

The amount of $\mathrm{CO}_{2}$ sequestered from the atmosphere

Under baseline climate change

With climate change mitigation efforts
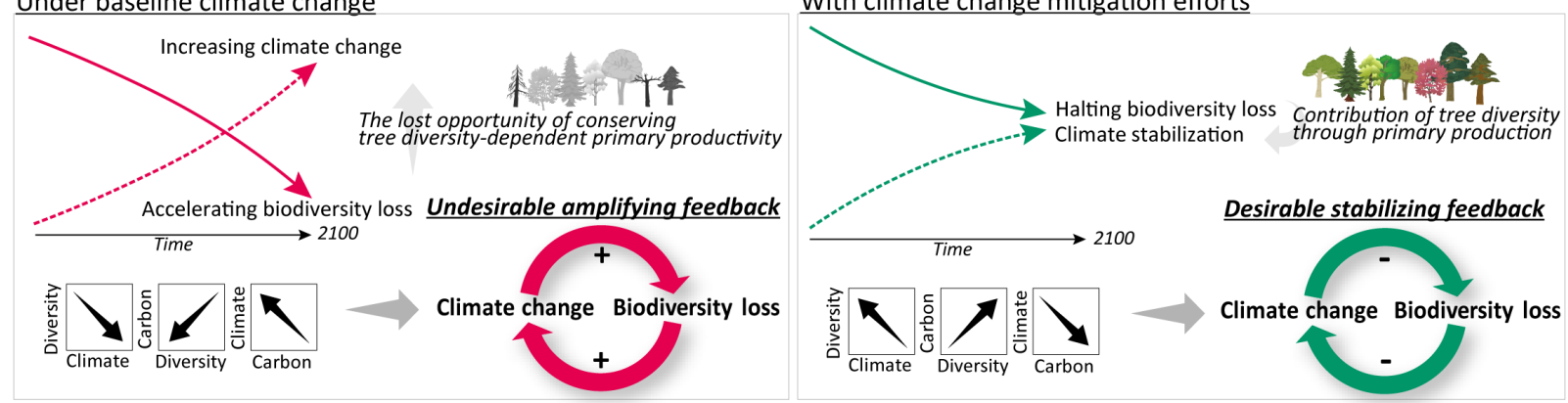

Figure 1. Schematic diagram of a possible pathway to biodiversity-based climate solutions.

There is much emphasis on the undesirable feedbacks where climate change drives biodiversity loss (magenta arrows feedback). Here, we highlight the contribution of an underutilized positive feedback in which biodiversity-dependent productivity could contribute to climate change mitigation (blueish green arrows feedback). The conservation and restoration of tree diversity could enhance this feedback and promote the desirable pathway whereby forest biodiversity contributes to climate change mitigation. 
(b) Effectiveness to alleviate species loss at the local scale

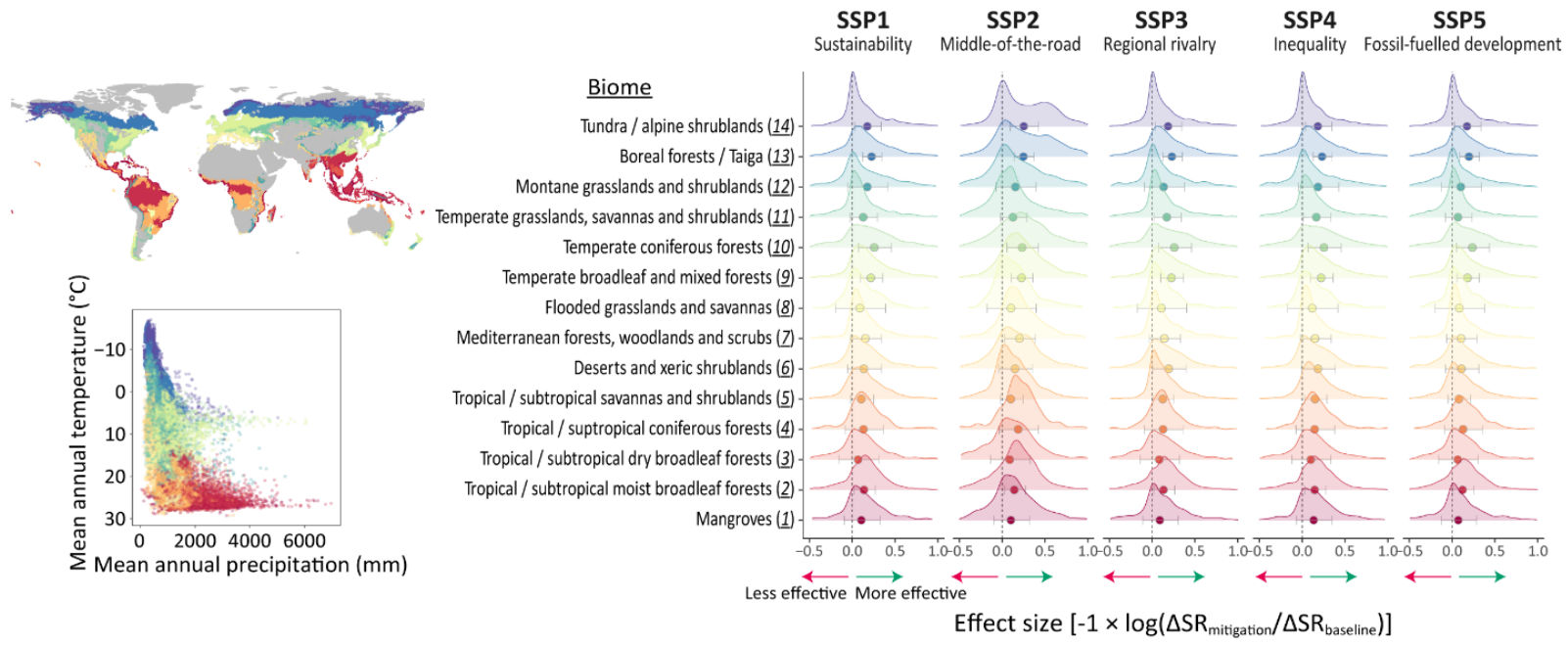

Figure 2. Biome-level projections in alleviating the loss of tree diversity from 2005 to 2070s. a) Map of biomes where trees are present, and the distribution of the coarse grids (at the spatial scale of the 30 arcminutes) within each biome along temperature and precipitation gradients (annual means for the period 1970-2000). Colours of the points of each biome correspond to those shown in the panel (b). b) Ridge density plots showing the effect sizes of an effective climate change mitigation policy on species loss $(\Delta \mathrm{SR})$, calculated as mean $\alpha$-diversity change within each of the coarse grids between 2005 and 2070s ( $n=32,670$ grids). Results are shown for the five SSPs. Ensembled results across the three GCMs are shown; the points and horizontal bars indicate means and their 95\% confidence intervals, respectively. When the effect sizes in each biome were converted into percentage changes, the consequences of mitigation efforts corresponded to approximately 3.0-61.3\% reductions in local tree species loss compared to the respective baseline scenario. Outliers are not shown for density plots. Results for each GCM are shown in Extended Data Figure 3. Numbers after biome names are consistently used in Figure 3, 4, Extended Data Figure 3, 4 and 6. 


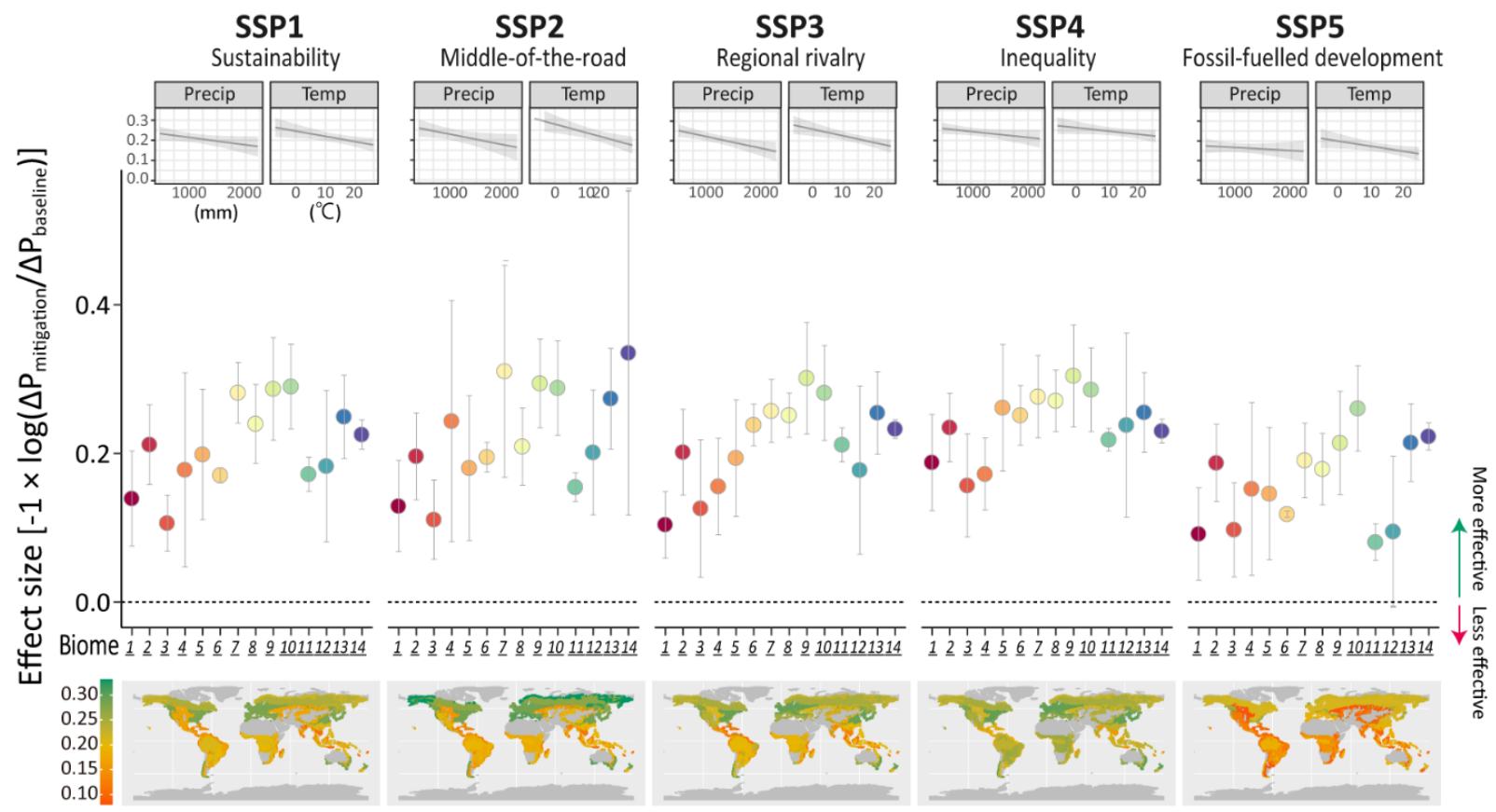

Figure 3. Biome-level projections in the effect of a climate change mitigation to alleviate the loss of tree diversity-dependent productivity $(\Delta \mathrm{P})$ from 2005 to 2070s. The effect sizes of $\Delta \mathrm{P}$ were calculated at the local scale (at the spatial scale of the 30 arcseconds) in 14 biomes that include trees ( $\mathrm{n}=\sim 115$ million grids). Results are shown for the five SSPs. Ensembled results for the effect size across the three GCMs are shown; the points and vertical bars indicate means and their 95\% confidence intervals, respectively. Colours of the points and numbers of each biome correspond to those shown in Fig. 2. When the effect sizes in each biome were converted into percentage changes, the consequences of mitigation efforts corresponded to approximately $8.8-38.9 \%$ reductions in productivity loss compared to baseline scenario. Results for each GCM are shown in Extended Data Figure 4. Small inset figures are the relations of the effect sizes with climate [annual mean temperature $\left({ }^{\circ} \mathrm{C}\right)$ and precipitation $\left.(\mathrm{mm})\right]$; all significant at $p<0.001$. Small maps are to visualize the effect sizes of each biome. Maps of the effect sizes at the coarse grid scale are shown in Extended Data Figure 5. 


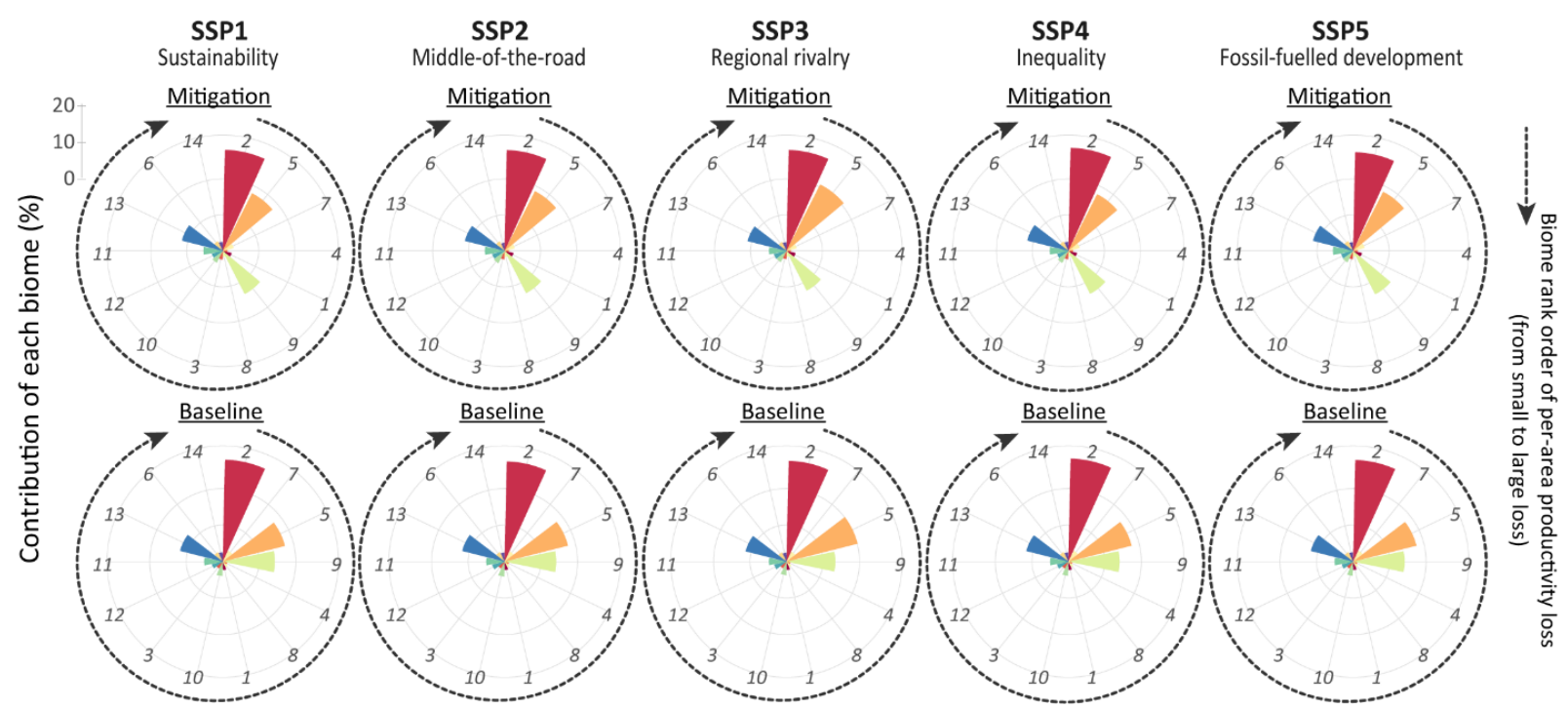

Figure 4. Biome-level sums in the effect of a climate change mitigation to alleviate the loss of tree diversity-dependent productivity $(\Delta \mathrm{P})$ from 2005 to 2070 s. Radar charts showing the proportional contribution of productivity loss resulting from species loss in each biome to global productivity loss under the mitigation (top) and baseline (bottom) scenarios (\%). Colours and numbers (shown in Italic) of each biome correspond to those shown in Fig. 2. The orders of biome in each radar chart are based on the per-area productivity loss of each biome (clockwise; from small to large loss), which are indicated with black dotted arrows. Mean values across the three GCMs are shown for the five SSPs. Results for each GCM are shown in Extended Data Figure 6. 


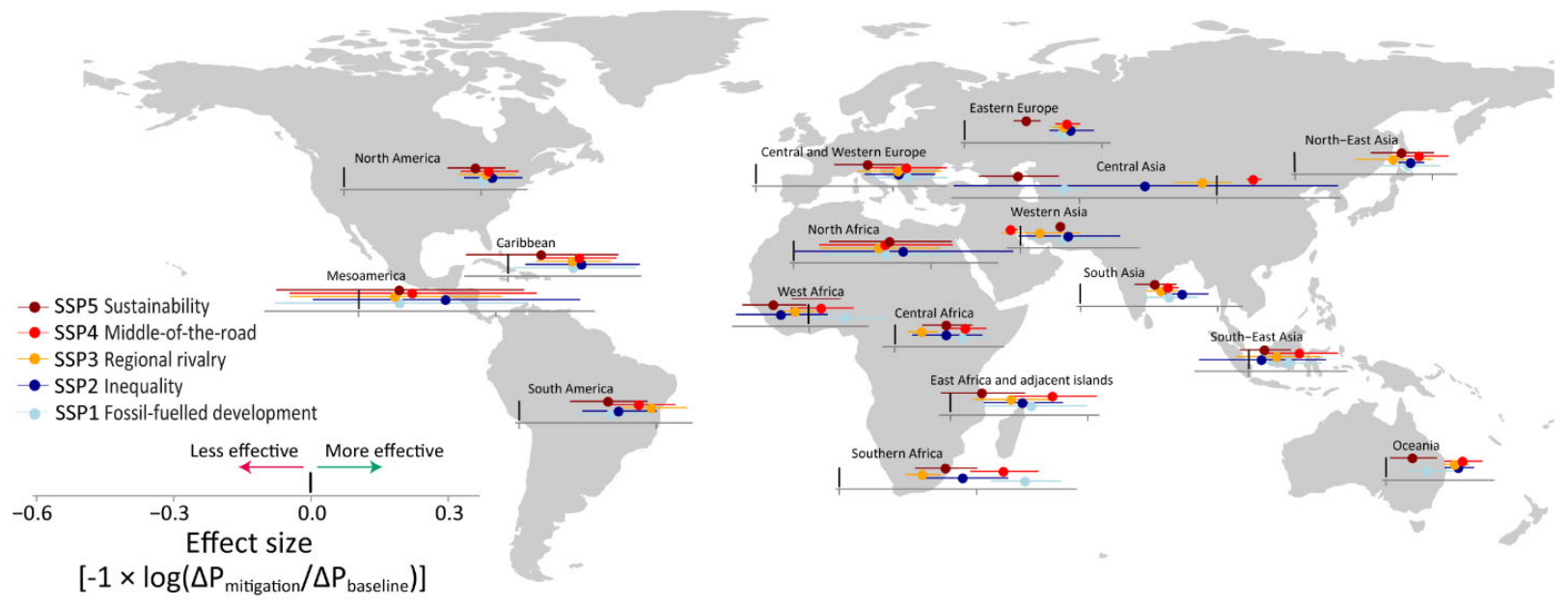

Figure 5. Subregion-level projections in the effect of a climate change mitigation to alleviate the loss of tree diversity-dependent productivity $(\Delta \mathrm{P})$ from 2005 to 2070s. The effect sizes of $\Delta \mathrm{P}$ were calculated at the local scale (at the spatial scale of the 30 arcseconds cells; $n=\sim 115$ million grids) for 17 subregions (based on the Intergovernmental Science-Policy Platform on Biodiversity and Ecosystem Services; IPBES ${ }^{7}$ ). Results are shown for the five SSPs. Ensembled results across the three GCMs are shown; the points and horizonal bars indicate means and their $95 \%$ confidence intervals, respectively. Vertical black bars indicate zero values of the effect size in each subregion (see the scale at the bottom left). Results for each GCM are shown in Extended Data Figure 7. 

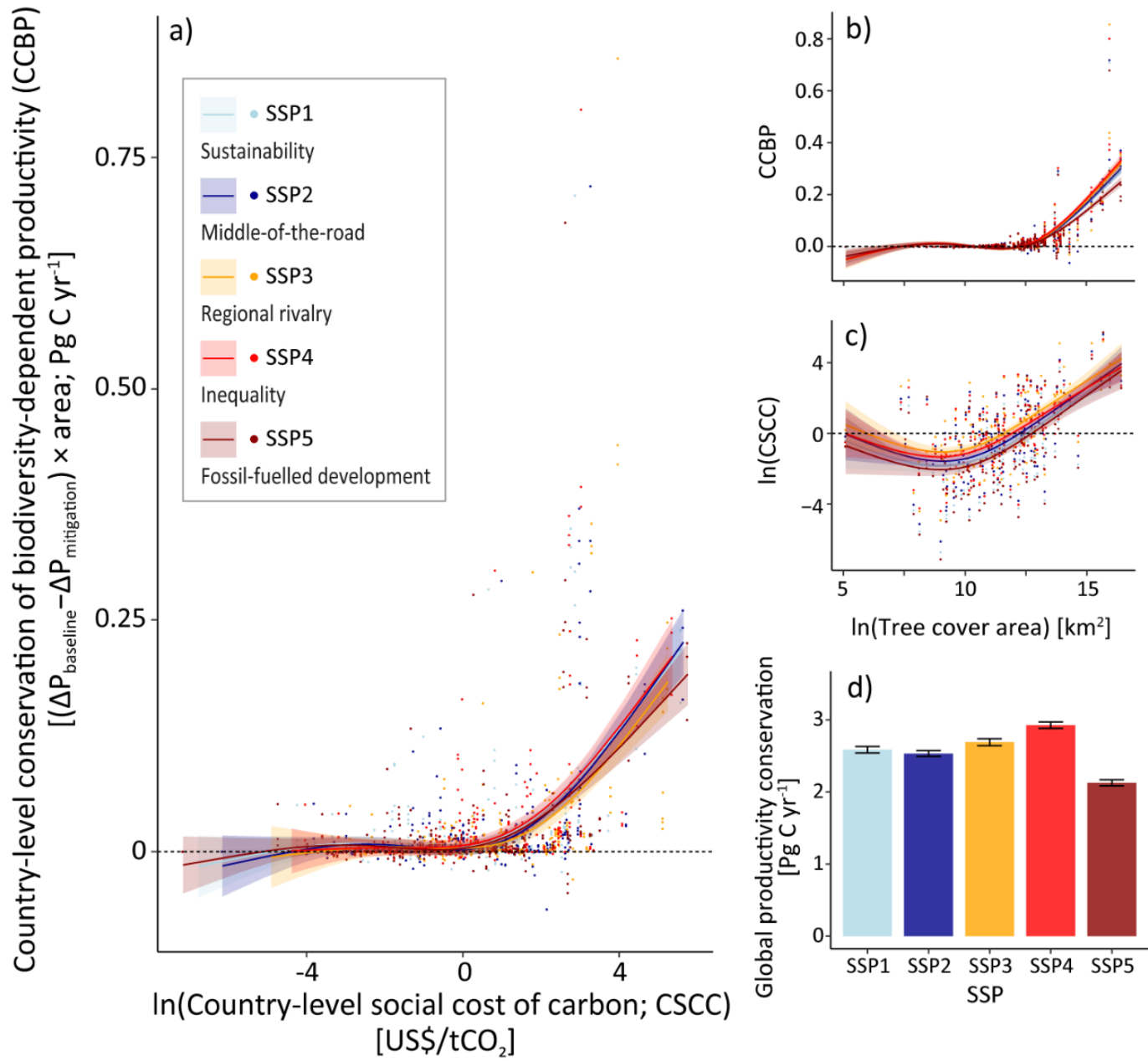

Figure 6. Country-level outcomes of a climate change mitigation to conserve tree diverstiydependent productivity. a) The relationships between the country-level social cost of carbon $\left[\mathrm{CSCC}^{33}\right]$, which is the marginal damages expected to occur in a particular country as a consequence of additional $\mathrm{CO}_{2}$ emissions, and the country-level conservation of tree diversity-dependent productivity [CCBP; the differences in local productivity changes, $\Delta \mathrm{P}$, between the two scenarios aggregated for each country]. The largest values (outliers) of CCBP are Brazil for all SSPs. Results for each GCM are shown in Extended Data Figure 8. b) and c) The relationships of the terrestrial area analysed for each country with the CCBP and the CSCC. The lines and shaded areas are the estimates based on a generalized additive mixed model and their $95 \%$ confidence intervals, respectively. Results are shown for the five SSPs. d) The sum of productivity conservation across countries for the five SSPs (mean \pm standard error across three GCMs). These estimates corresponded to $4.9-6.7 \%$ of total net primary productivity in the terestrial areas analysed. 


\section{METHODS}

Our workflow of how to estimate proportional changes in species richness and forest productivity as well as absolute changes in net primary productivity at the local scale is visualized in Figures S1 and S2. We refer to the Supplementary Information for a full description of the methods, and only provide a succinct summary of our approach here.

\section{Species distribution modelling}

Spatially-explicit observations of tree and shrub species (hereafter, referred to as trees) were available from a previous study ${ }^{28}$. Also see Supplementary Table 1 for the protocol of our species distribution modelling, which relied on climate and land-use variables. Note that the modelling was previously conducted at a spatial resolution of 30 arcminutes (hereafter, coarse grids). Here we extended the modelling to a resolution of 30 arcseconds (hereafter, fine grids) to improve our approximation of biodiversity-dependent productivity (see below). However, the modelling for species distributions at the fine scale was only possible for the present period, because future land-use variables were only available at the scale of coarse grids. We sampled one occurrence record per grid for all species at both spatial resolutions. To avoid the effect of model inaccuracy from small sample size, we limited our analysis to species that had occurrence records of 30 and more ${ }^{53}$. These resulted in 1,755 and 934 target tree species at a spatial resolution of fine and coarse grids, respectively. See Supplementary Data 1 for the list of these target species.

For the present period, we obtained a dataset of 19 bioclimatic variables, calculated from monthly minimum temperature, maximum temperature, and precipitation at the resolution of fine grids downloaded from the WorldClim 1.4 (www.worldclim.org) ${ }^{54}$. Then, we obtained land-use variables at a resolution of fine grids from the MODIS (Moderate resolution Imaging Spectroradiometer) Land Cover Type for the year 2005 (glcf.umd.edu/data/lc). We used land cover classes of the global vegetation classification scheme of the International Geosphere-Biosphere Programme (www.igbp.net) as a categorical variable in our models of species distribution. One of the five land-use types (cropland, pasture, forest, other natural lands, and settled land) was assigned to each of the fine grids. For future scenarios, we focused on a mitigation scenario and a high-emission baseline scenario based on the Representative Concentration Pathways (RCPs): the mitigation scenario aimed to stabilize climate change by the end of the 21st century, whereas the baseline scenario assumed increasing greenhouse gas (GHG) emissions and thus climate change over time ${ }^{28}$. We set the target period for analyses as the 2070s. We used future climatic variables based on three General Circulation Models (GCMs) included in the Fifth Coupled Model Inter-Comparison Project experiment: MIROC-ESM-CHEM ${ }^{55}$, HadGEM2-ES ${ }^{56,57}$, and GFDL-CM3 ${ }^{58}$, downloaded from the WorldClim 1.4 (www.worldclim.org) ${ }^{54}$. All 19 bioclimatic variables for the future were calculated using the same method as for the current climate. We 
estimated changes in future land-use under the mitigation and baseline scenarios ${ }^{27}$ with $\mathrm{AIM} / \mathrm{CGE}^{59}$, a computable general equilibrium model representing the entire global economy. AIM/CGE implements climate change mitigation in the form of a global uniform carbon tax on GHG emissions from the agriculture, land-use, and energy sectors. The allocation of land by sector for 17 regions is formulated as a multinomial logit function to reflect differences in substitutability across land rent, and regional land-use is further downscaled to the scale of coarse grids based on spatially explicit attainable yields ${ }^{60}$. In this study, we relied on the Shared Socioeconomic Pathways (SSPs) framework $^{61}$. The SSPs are based on five narratives describing how socioeconomic factors may change over the next century, considering changes in population, GDP, energy, emissions, and land-use: challenges to adaptation and mitigation are both low (SSP1: sustainability) or both high (SSP3: regional rivalry); low challenges to mitigation are combined with high challenges to adaptation (SSP4: inequality); high challenges to mitigation are combined with low challenges to adaptation (SSP5: fossil-fuelled development); intermediate challenges exist for both adaptation and mitigation (SSP2: middle-of-the-road). Also, refer to Supplementary Table 2 for these narratives. The SSPs employ a concept called scenario matrix architecture, which has a two-dimensional space comprising combinations of socioeconomic patterns, represented by the SSPs, and climate change mitigation levels, represented by RCPs. For our mitigation scenarios, we used each SSP, combined with the RCP with the lowest radiative forcing level. SSPs 1, 2, 4, and 5 were combined with RCP 2.6. SSP3 was combined with RCP3.4 because the SSP3-RCP2.6 combination was found to be incompatible ${ }^{61}$. We used the high-emission baseline condition in each SSP for the baseline scenario, assuming the absence of additional climate policy and efforts. Given that land-use scenarios explicitly incorporated areas for bioenergy crops and afforestation for GHG mitigation activity, which did not exist in land-use data in the current condition, bioenergy crops and afforestation were merged into cropland and forests, respectively.

Using these variables, we employed MaxEnt v3.3 $3^{62}$ for predicting the current and future probability of occurrence of target species. First, by using the five land-use and 19 bioclimatic variables, we generated all possible combinations of these explanatory variables. We then excluded explanatory variables showing collinearity. We selected the most parsimonious combination of explanatory variables based on corrected Akaike information criterion ${ }^{63}$. Among the final models developed for all species, we discarded those with poor performance for subsequent analyses based on 10-fold cross validation, as follows. We used models with Boyce index ${ }^{64}>0$ based on the $95 \%$ confidence interval for the subsequent analyses. To obtain a map of suitable habitat for each species under the current conditions, the average value of the relative probability of occurrence calculated by the 10-fold cross-validation was converted into a binary map. We applied the average of the $90 \%$ sensitivity threshold to minimize the false-negative fractions and to avoid underestimating the suitable habitat area ${ }^{65}$. For future scenarios, we explicitly included a species' ability to disperse and track the shifting climate ${ }^{28}$ by considering dispersal traits ${ }^{66}$. Here dispersal 
distance per generation was estimated from the formula based on earlier work ${ }^{66}$. Based on this approach, we obtained habitat maps for individual species. The possible changes in areas hospitable to species under different future scenarios were described earlier ${ }^{28}$ : briefly, the losses of suitable habitats due to the combined effects of climate and land-use were estimated to be smaller in the mitigation scenario than in the baseline scenario (e.g., approximately $17-28 \%$ and $22-36 \%$ for the mitigation and baseline scenario, respectively, across a wide range of organism groups).

\section{Species richness and productivity estimation}

We projected spatial distributions of individual species for the year 2005 and the 2070s at a spatial resolution of 30 arcminutes (coarse grids; $n=32,670$ ). For both estimates, we obtained the total number of species present in each coarse grid (hereafter, $\gamma$-diversity). For the former year, we also projected spatial distributions of individual species at the spatial resolution of 30 arcseconds (fine grids; $n=115,426,714)$. Based on these projections, we calculated changes in species richness at the scale of fine grids (hereafter, $\alpha$-diversity) from 2005 to 2070s for different scenarios of climate and land-use changes. We first obtained species-area and endemics-area relationships (SARs and EARs, respectively) for the year 2005 that were unique to each of the coarse grids. If all fine grids were forested, a coarse grid had 3,600 fine grids. These relationships were used to estimate $\alpha$-diversity in the year 2005 ( $n=32,670$ grids; each coarse grid had a unique mean value of $\alpha$-diversity). Note that it was infeasible to directly estimate the temporal changes in $\gamma$-diversity because future spatial distributions were estimated only for a subset of species present in the 2005 data (i.e., widespread common species). Instead, we used the number of these common species that went extinct from or immigrated into a given coarse grid by the 2070s for estimating the number of other subordinate species (that were excluded in the MaxEnt analysis for the period of 2070s because of limited occurrence at the scale of 30 arcminutes) that went co-extinct or co-immigrated.

To implement this, we first ran two spatially explicit simulations for species co-extinction and co-immigration. In an artificial landscape with 3,600 homogeneous grids, we randomly drew between 5 and 80 species with total occurrence between 500 and 180,000 individuals, based on a lognormal species abundance distribution (SAD) with randomly assigned parameters $\mu$ and $\sigma$ of SADs reported in different biomes ${ }^{67-69}$. To consider many possibilities of spatial patterns of tree individuals in different biomes, we randomly assigned individuals of each species to each of the 3,600 grids. For each of these artificial meta-communities, we calculated mean $\alpha$-diversity (number of species per grid), $\gamma$-diversity (number of species per landscape), Whittaker's multiplicative $\beta$-diversity, and Shannon's evenness (across the grids) ${ }^{69}$. We also constructed SARs for estimating species richness at the smallest spatial scale. Here we defined common species as abundant species that had an abundance rank of $25 \%$ or below. For co-extinction simulation, we randomly made some of (up to half of) these common species extinct from a meta-community. Other rare species that were present in the same grid with these extinct common species were also forced to extinction, assuming that 
these grids became no longer habitable for any species. For co-immigration simulations, we assumed that an artificial meta-community resulted from additional immigration of both common and rare species. We again randomly assigned some of (up to half) the species as common and removed them from the meta-community to construct a pre-immigration meta-community. We also removed individuals of other species that were present in the same grid with these common species, assuming that these grids became newly hospitable in a post-immigration meta-community. We repeated the above co-extinction and co-immigration simulations 25,000 times, respectively. Based on the results from these artificial landscapes, we used extreme gradient boosting (XGBoost) ${ }^{70}$ to obtain machine learning regressions for predicting the number of species co-extinct and co-immigrated based on other information described above.

We applied these regressions to the results of species distribution modelling (also see Fig. $\mathrm{S} 2$ for a schematic diagram). By comparing the number of widespread common species in each coarse grid between the year of 2005 and 2070s, we obtained the number of common species extinct or immigrated. This information was combined with our XGBoost regressions to obtain the potential number of subordinate species co-extinct and co-immigrated in each coarse grid. When we observed extinctions of some species for the 2070s in a given coarse grid, we converted this total number of species lost into a proportion of habitats that was required for losing these species based on the unique $\mathrm{EAR}^{71}$. When we observed immigration by some species for the $2070 \mathrm{~s}$ in a coarse grid, then we converted this total number of species gained into a proportion of habitat that was required to gain these species based on the unique SAR ${ }^{71}$. By multiplying these proportional changes in the habitable area for the period of 2070s with species richness values at the scale of fine grids, which were derived from the unique SARs in the year 2005, we obtained the values of $\alpha$-diversity in the 2070s. In some coarse grids, it was not possible to obtain unique SARs or EARs for reasons such as low $\gamma$-diversity. In such a case, we assumed that proportional changes in the habitable areas between the two periods were estimated by relying on an empirical SAR with the slope value of 0.3 in $\log$-log space s2,73 $^{\text {. Based }}$ on the changes in $\gamma$-diversity, we estimated the values of $\alpha$-diversity in the 2070 s. Note that, likewise the year 2005, each of the coarse grids in the period of 2070s also had a single unique value of $\alpha$ diversity $(n=32,670)$.

We calculated proportional changes in $\alpha$-diversity from the year 2005 to the period of $2070 \mathrm{~s}$ $(\%)$ and converted them into proportional changes in forest productivity (\%) based on parameters of the elasticity of substitution $(\theta)$, which we estimated for forest biomes worldwide ${ }^{17}$. The elasticity of substitution can be used to estimate forest productivity based on proportional changes in tree species richness (i.e., $\alpha$-diversity). The values of the elasticity of substitution were originally estimated based on forest inventory datasets collected at the local spatial scale ${ }^{17}$. For avoiding a potential mismatch due to scaling issues ${ }^{23,74}$, we estimated the changes in productivity at the scale of fine grids. We used a net primary productivity (NPP) dataset estimated using the MODIS imagery ${ }^{26}$ for the year 2005 (note, in the terrestrial biomes analysed here, total NPP was approximately $43.78 \mathrm{Pg} \mathrm{C} \mathrm{yr}^{-1}$ ). We 
obtained NPP values at the scale of fine grids. Here we assumed that all fine grids in a given coarse grid showed the equivalent changes in productivity in a proportional scale, reflecting the mean change in $\alpha$-diversity expected to occur in that coarse grid. Based on these estimations, we have obtained absolute changes in forest productivity $\left(\mathrm{kg} \mathrm{C} \mathrm{m}^{-2} \mathrm{yr}^{-1}\right)$ for different scenarios of climate/land-use changes at the scale of fine grids. Note that our analyses for tree diversity and productivity changes were conducted for the grids where tree species were observed in the present period and $\theta$ values were available (resulting in the analysis of $\sim 115$ million fine grids); thus, the results are also shown for non-forested biomes.

\section{Data analyses}

We summarized our results at different spatial scales from local to global. Here, the fine grids are defined as the local scale. We also focused on the scales of countries and biomes. Terrestrial biome categories are based on the 14 terrestrial ecoregions used by the World Wildlife Fund (www.worldwildlife.org). We have obtained information for areas and names of individual countries from Natural Earth (www.naturalearthdata.com). To be relevant for global policy, we have summarized results also at the scale of the subregion used in the Intergovernmental Science-Policy Platform on Biodiversity and Ecosystem Services (IPBES; www.ipbes.net/deliverables/2b-regionalassessments). For some territories and nations that are not explicitly classified into regional categories, we assigned their subregions based on their geographical locations.

To quantify the effect sizes of mitigation efforts on conservation of species and productivity, we calculated the reductions in local-scale loss of species $(\Delta \mathrm{SR})$ and productivity $(\Delta \mathrm{P})$ as a log ratio scale, which assumes that zero corresponds to no difference between the two scenarios. Estimates based on the baseline and mitigation scenarios were used for the denominator (control; $\Delta \mathrm{SR}_{\text {baseline }}$ and

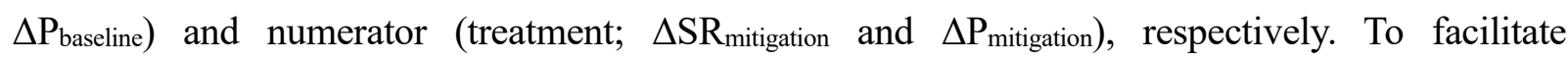
interpretation, we multiplied -1 with the effect sizes and thereby positive and negative values, respectively, indicate a more and less effective climate change mitigation policy in reducing species loss and the associated productivity loss (also see a schematic diagram in Fig. S3). To ensemble results across the three GCMs, we obtained global means and the associated 95\% confidence intervals for each SSP scenario. We repeated the above calculations at the biome-, IPBES subregion-, and countryscale. For biome-level analyses, we used a mixed-effects meta-regression with the effect size as a response variable, the GCMs as a random effect, and climate conditions (mean annual temperature or precipitation of biomes) as a moderator.

Then, we focused on the relationship between the country-level social cost of carbon [CSCC $\left(\mathrm{US} \$ \mathrm{tCO}_{2}{ }^{-1}\right)^{33}$, estimated for each of SSPs] and the country-level reduction in forest productivity loss under a given SSP. Here we were interested in the country-level loss of productivity (absolute changes within each country), instead of the productivity loss per area that can give the average estimates of local productivity changes within a focal area (e.g., proportional changes within each country). We 


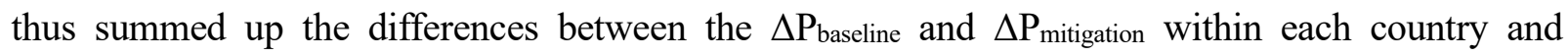
multiplied these values by the area of each country $\left(\mathrm{Pg} \mathrm{C} \mathrm{yr}^{-1}\right)$. For each of the individual combinations of SSPs and GCMs, we relied on a generalized additive model (GAM) with the CSCC as an explanatory variable. To ensemble results across the GCMs, we used a generalized additive mixed model (GAMM) with the GCMs as a random effect and the CSCC as an explanatory variable. We additionally checked if the results were affected by land area, using the GAMMs. Lastly, we summed up the reduction in productivity loss across all countries, under each of SSPs and GCMs. This gave us the estimate of global productivity conservation, corresponding to the value, global $\sum$ $\left(\Delta \mathrm{P}_{\text {baseline }}-\Delta \mathrm{P}\right.$ mitigation $)$.

Acknowledgments The paper was formed, analysed, and written through workshops hosted by the National Center for Ecological Analysis and Synthesis (NCEAS), USA. FI, JC, and LED acknowledge support from the US NSF Long-Term Ecological Research (LTER) Network Communications Office (DEB-1545288). ASM and KO acknowledge support from the Ichimura New Technology Foundation. ASM, KO, TM and HO were funded by the Environment Research and Technology Development Fund (ERTDF; JPMEERF15S11420) of the Environmental Restoration and Conservation Agency (ERCA) of Japan. ASM was supported by the Grants-in-Aid for Scientific Research of the Japan Society for the Promotion of Science (JSPS; 15KK0022). FI acknowledges support from a US National Science Foundation (NSF) CAREER award (DEB-1845334). AG was supported by the Liber Ero Chair in Biodiversity Conservation. ML was supported by the TULIP Laboratory of Excellence (ANR-10-LABX-41). TM and HO were funded by the ERTDF (JPMEERF20202002) of the ERCA. We thank Yuta Kobayashi and Risa Inoue (Yokohama National University) to help organize the data. Mizuki Maeda provided illustrations for the conceptual diagram.

Author contributions ASM designed the study with critical inputs from FI, RS and TN. HO and TM analysed species distributions, and ASM and OK contributed to the following analyses. JC, AG and ASM developed a conceptual diagram of biodiversity-dependent climate solutions. HO and TN contributed to developing the protocol of species distribution modelling. WT contributed to developing land-use data. ASM, LD AG, RS and FI prepared drafts to have further discussions among all authors. AJW, JC, YH, PBR and ML provided substantial inputs on drafts and revisions of the paper.

Competing interests The authors declare no competing interests

\section{Additional information}

\section{Supplementary materials}


Supplementary Information for Methods, Table 1-2, and Figure 1-6.

Extended Data Figures 1-10.

Data availability The source data underlying figures (Supplementary Data 1-6) are archived in the Dryad repository: https://doi.org/10.5061/dryad.vq83bk3s2.

Code availability The code that support the findings of this study are available from the corresponding author upon reasonable request.

\section{References}

53 Wisz, M. S. et al. Effects of sample size on the performance of species distribution models. Divers Distrib 14, 763-773, doi:10.1111/j.1472-4642.2008.00482.x (2008).

54 Hijmans, R. J., Cameron, S. E., Parra, J. L., Jones, P. G. \& Jarvis, A. Very high resolution interpolated climate surfaces for global land areas. Int J Climatol 25, 1965-1978, doi:10.1002/joc.1276 (2005).

55 Watanabe, S. et al. MIROC-ESM 2010: model description and basic results of CMIP5-20c3m experiments. Geoscientific Model Development 4, 845-872, doi:10.5194/gmd-4-845-2011 (2011).

56 Collins, W. J. et al. Development and evaluation of an Earth-System model - HadGEM2. Geoscientific Model Development 4, 1051-1075, doi:10.5194/gmd-4-1051-2011 (2011).

57 Jones, C. D. et al. The HadGEM2-ES implementation of CMIP5 centennial simulations. Geoscientific Model Development 4, 543-570, doi:10.5194/gmd-4-543-2011 (2011).

58 Griffies, S. M. et al. The GFDL CM3 Coupled Climate Model: Characteristics of the Ocean and Sea Ice Simulations. Journal of Climate 24, 3520-3544, doi:10.1175/2011jcli3964.1 (2011).

59 Fujimori, S., Hasegawa, T. \& Masui, T. AIM/CGE V2.0: Basic Feature of the Model. (Springer Nature Singapore, 2017).

60 Hasegawa, T., Fujimori, S., Ito, A., Takahashi, K. \& Masui, T. Global land-use allocation model linked to an integrated assessment model. Science of the Total Environment 580, 787796, doi:10.1016/j.scitotenv.2016.12.025 (2017).

61 Riahi, K. et al. The Shared Socioeconomic Pathways and their energy, land use, and greenhouse gas emissions implications: An overview. Global Environmental Change 42, 153 168, doi:10.1016/j.gloenvcha.2016.05.009 (2017).

62 Phillips, S. J., Anderson, R. P. \& Schapire, R. E. Maximum entropy modeling of species geographic distributions. Ecol Model 190, 231-259, doi:10.1016/j.ecolmodel.2005.03.026 (2006).

63 Warren, D. L. \& Seifert, S. N. Ecological niche modeling in Maxent: the importance of model 
complexity and the performance of model selection criteria. Ecol Appl 21, 335-342, doi:10.1890/10-1171.1 (2011).

64 Boyce, M. S., Vernier, P. R., Nielsen, S. E. \& Schmiegelow, F. K. A. Evaluating resource selection functions. Ecol Model 157, 281-300, doi:10.1016/s0304-3800(02)00200-4 (2002).

65 Pearson, R. G., Dawson, T. P. \& Liu, C. Modelling species distributions in Britain: a hierarchical integration of climate and land-cover data. Ecography 27, 285-298, doi:10.1111/j.0906-7590.2004.03740.x (2004).

66 Tamme, R. et al. Predicting species' maximum dispersal distances from simple plant traits. Ecology 95, 505-513, doi:10.1890/13-1000.1 (2014).

67 Engen, S., Lande, R., Walla, T. \& DeVries, P. J. Analyzing spatial structure of communities using the two-dimensional poisson lognormal species abundance model. The American Naturalist 160, 60-73, doi:10.1086/340612 (2002).

68 He, F. \& Gaston, K. J. Occupancy, spatial variance, and the abundance of species. The American Naturalist 162, 366-375, doi:10.1086/377190 (2003).

69 Magurran, A. E. \& McGill, B. J. Biological diversity. (Oxford University Press, 2011).

70 Chen, T. \& Guestrin, C. in Tthe 22nd ACM SIGKDD International Conference on Knowledge Discovery and Data Mining. 785-794.

71 He, F. \& Hubbell, S. P. Species-area relationships always overestimate extinction rates from habitat loss. Nature 473, 368-371, doi:10.1038/nature09985 (2011).

72 Neigel, J. E. Species-area relationships and marine conservation. Ecol Appl 13, 138-145, doi:10.1890/1051-0761(2003)013[0138:saramc]2.0.co;2 (2003).

73 Rogan, J. E. \& Lacher, T. E. Impacts of Habitat Loss and Fragmentation on Terrestrial Biodiversity. doi:10.1016/b978-0-12-409548-9.10913-3 (2018).

74 Chase, J. M. \& Leibold, M. A. Spatial scale dictates the productivity-biodiversity relationship. Nature 416, 427-430, doi:10.1038/416427a (2002). 

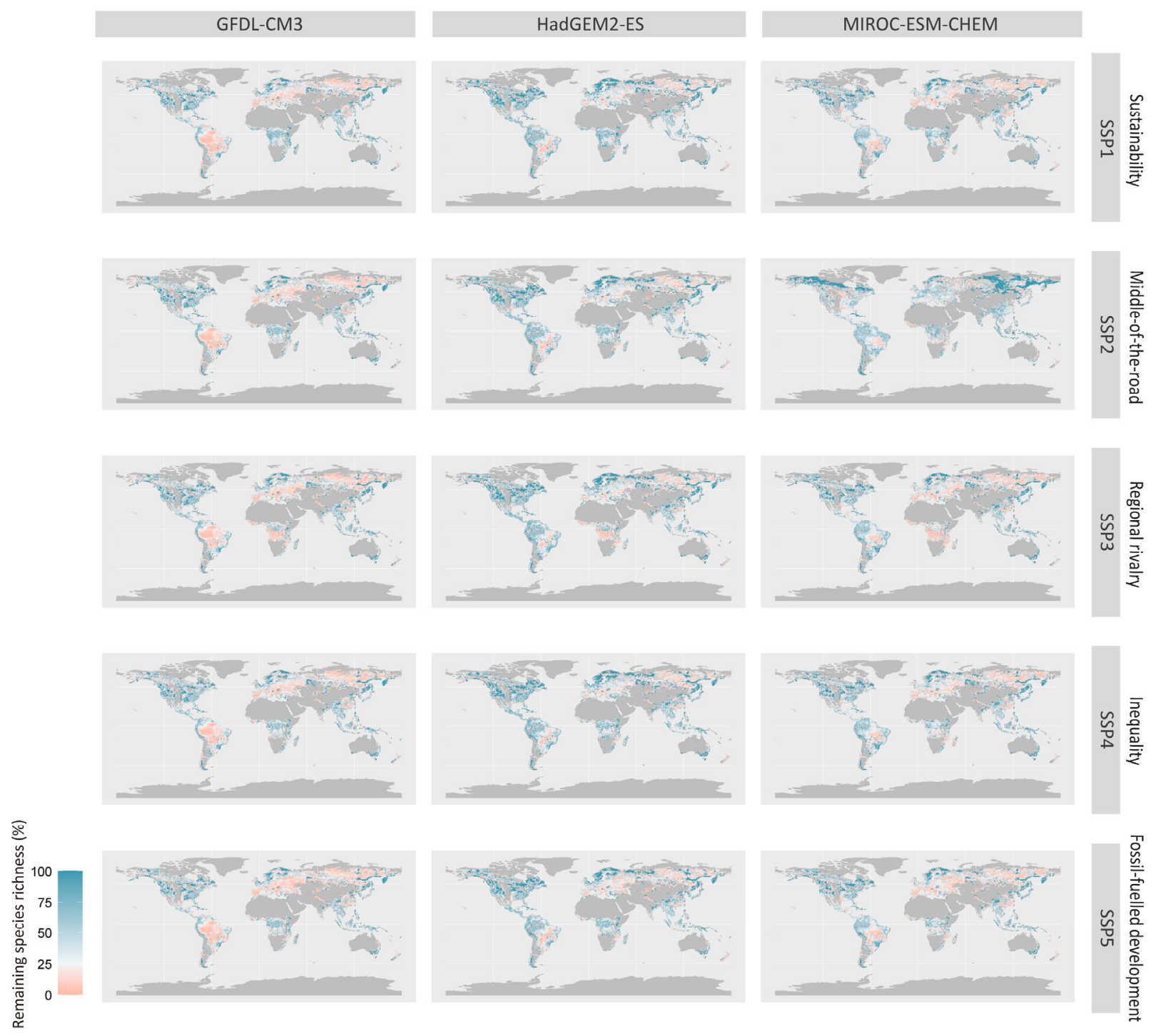

Extended Data Figure 1. Maps showing the projected changes in tree diversity under the mitigation scenarios from 2005 to 2070s. The proportional changes (\%) in mean $\alpha$-diversity (remaining species richness estimated at the fine grid-scale) are shown within each of the coarse grids ( $\mathrm{n}=32,670$ grids). Results are shown for the five Shared Socioeconomic Pathways (SSPs) and the three General Circulation Models (GCMs). 

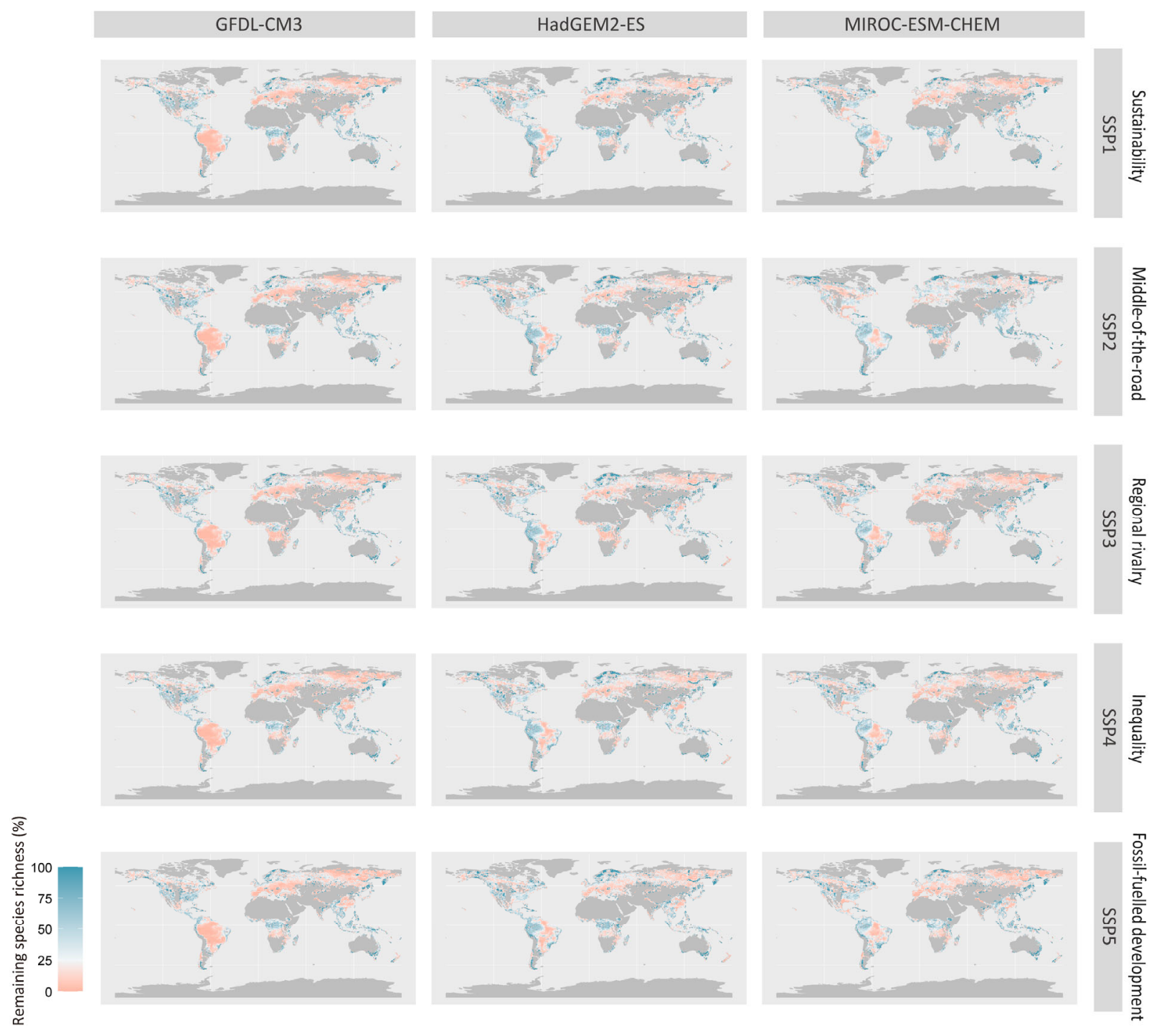

Extended Data Figure 2. Maps showing the projected changes in tree diversity under the baseline scenarios from 2005 to 2070s. The proportional changes (\%) in mean $\alpha$-diversity (remaining species richness estimated at the fine grid-scale) are shown within each of the coarse grids ( $\mathrm{n}=32,670$ grids). Results are shown for the five Shared Socioeconomic Pathways (SSPs) and the three General Circulation Models (GCMs). 
Tundra / alpine shrublands (14)

Boreal forests / Taiga ( $\underline{13})$

Montane grasslands and shrublands (12)

Temperate grasslands, savannas and shrublands $(\underline{11})$ -

Temperate coniferous forests $(\underline{10})$

Temperate broadleaf and mixed forests $(\underline{9})$

Flooded grasslands and savannas (요)

Mediterranean forests, woodlands and scrubs ( $\underline{7})$

Deserts and xeric shrublands ( $\underline{6})$

Tropical / subtropical savannas and shrublands (ㅁ)

Tropical / suptropical coniferous forests (4)

Tropical / subtropical dry broadleaf forests ( $\underline{3})$

Tropical / subtropical moist broadleaf forests (2)

Mangroves (1)

Tundra / alpine shrublands (14)

Boreal forests / Taiga ( $\underline{13})$

Montane grasslands and shrublands (12)

Temperate grasslands, savannas and shrublands (11)

Temperate coniferous forests $(\underline{10})$

Temperate broadleaf and mixed forests $(\underline{g})$

Flooded grasslands and savannas $(\underline{8})$

Mediterranean forests, woodlands and scrubs (그)

Deserts and xeric shrublands (무)

Tropical / subtropical savannas and shrublands (ㅁ)

Tropical / suptropical coniferous forests (4)

Tropical / subtropical dry broadleaf forests (ㄱ)

Tropical / subtropical moist broadleaf forests (2) -

Mangroves (1)

Tundra / alpine shrublands (14)

Boreal forests / Taiga ( $\underline{13})$

Montane grasslands and shrublands (12)

Temperate grasslands, savannas and shrublands (11)

Temperate coniferous forests $(\underline{10})$

Temperate broadleaf and mixed forests $(\underline{9})$

Flooded grasslands and savannas $(\underline{8})$

Mediterranean forests, woodlands and scrubs ( $\underline{7})$

Deserts and xeric shrublands $(\underline{6})$

Tropical / subtropical savannas and shrublands ( $\underline{5})$

Tropical / suptropical coniferous forests (4)

Tropical / subtropical dry broadleaf forests ( $\underline{3})$

Tropical / subtropical moist broadleaf forests (2)

Mangroves ( 1 )
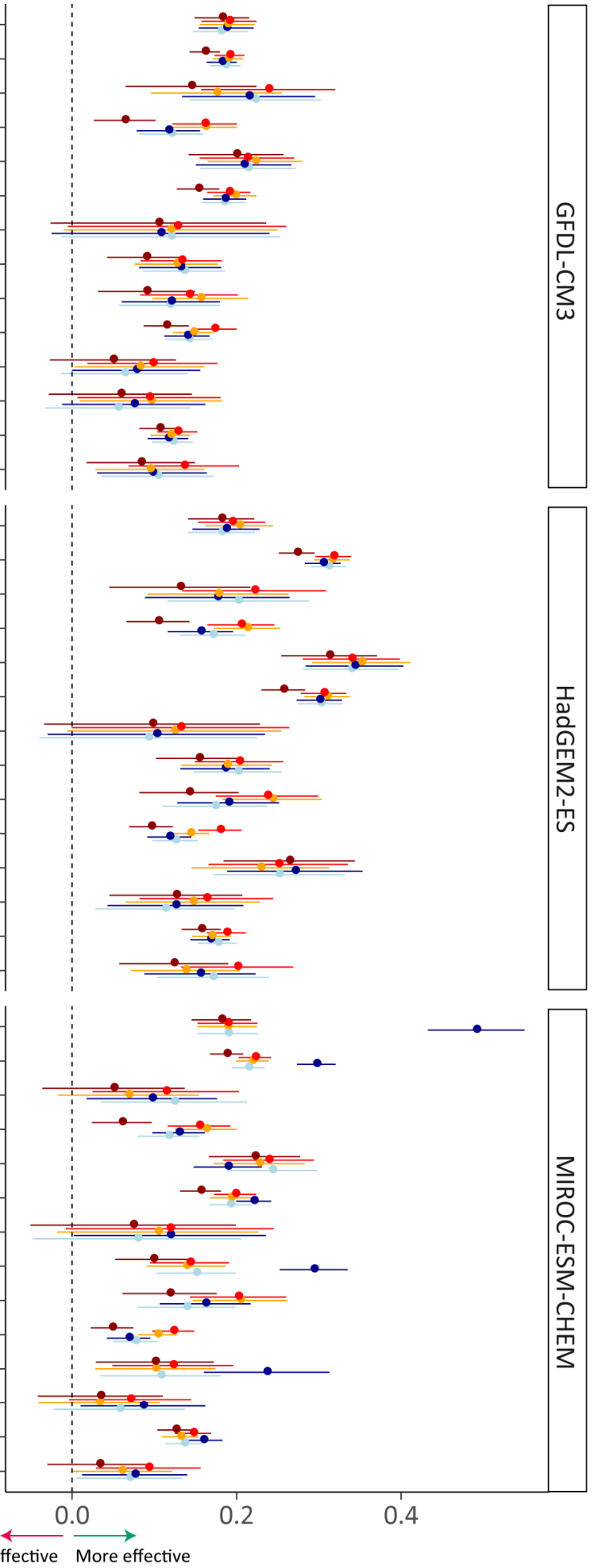

ffectiveness to alleviate species loss at the local scale

$\left[-1 \times \log \left(\Delta S R_{\text {mitigation }} / \Delta S R_{\text {baseline }}\right)\right]$

$\begin{array}{lllll}\rightarrow \text { SSP1 } & \bullet \text { SSP2 } & \rightarrow \text { SSP3 } & \rightarrow \text { SSP4 } & \bullet \text { SSP5 } \\ \text { Sustainability } & \text { Middle-of-the-road } & \text { Regional rivalry } & \text { Inequality } & \text { Fossil-fuelled development }\end{array}$


Extended Data Figure 3. Biome-level projections in the effects of a climate change mitigation to alleviate the loss of tree diversity $(\Delta S R)$ from 2005 to 2070s. The effect sizes [inverse of $\log ($ mitigation/baseline $)]$ of $\Delta \mathrm{SR}$ were estimated based on mean $\alpha$-diversity values within each of the coarse grids (the total number of the coarse grids $=32,670$ ). The effect size is shown as a log ratio scale; zero corresponds to the true absence of the outcome. Positive and negative values of effect size indicate more and less effectiveness of mitigation policy, respectively (green and red arrow, respectively). The points and horizontal bars indicate means and their 95\% confidence intervals, respectively. Results are shown for the five Shared Socioeconomic Pathways (SSPs: SSP1, sustainability; SSP2, middle-of-the-road; SSP3, regional rivalry; SSP4, inequality; SSP5, fossilfuelled development) and the three General Circulation Models (GCMs). Results are also provided as Supplementary Data 2. 


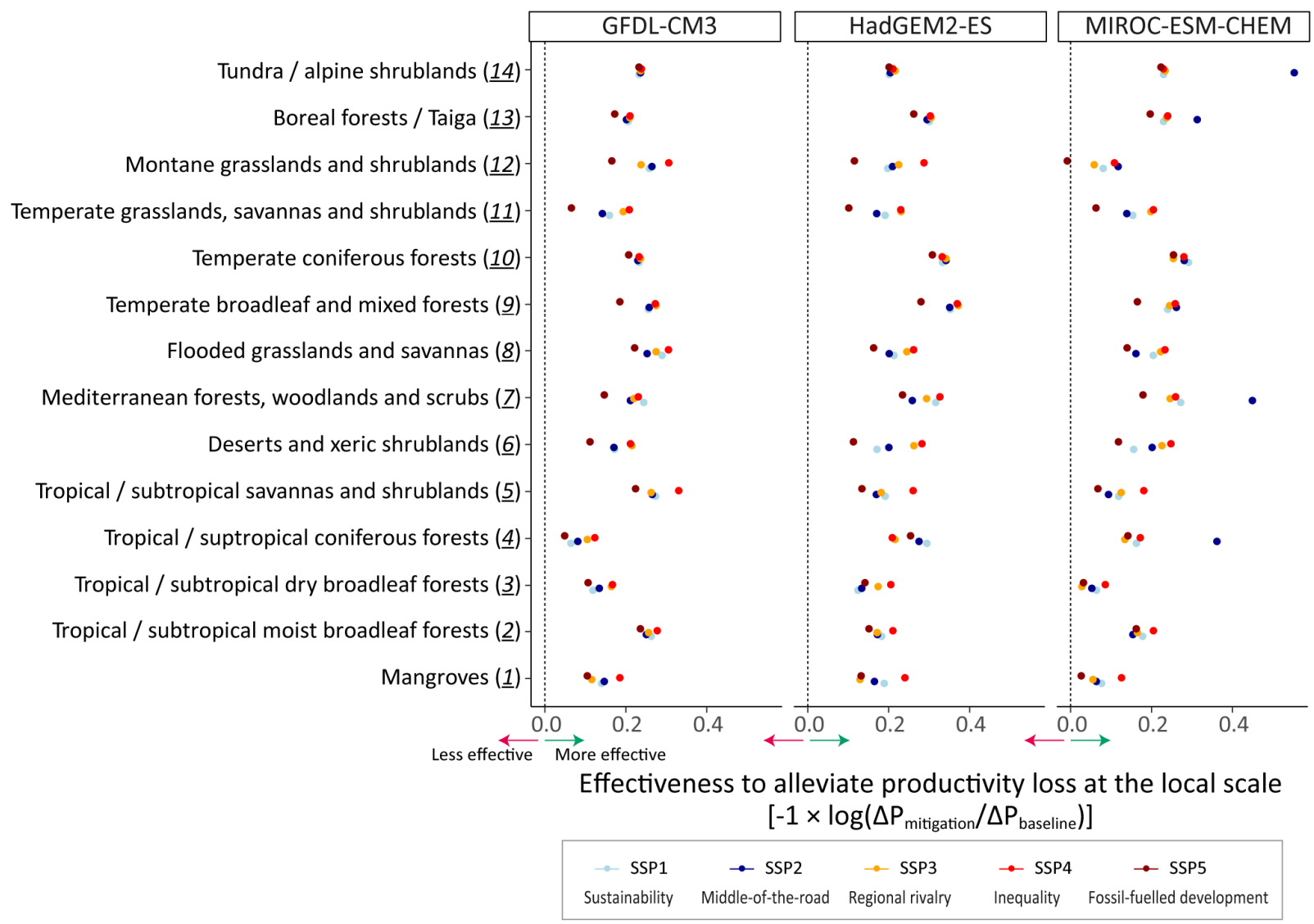

Extended Data Figure 4. Biome-level projections in the effects of a climate change mitigation to alleviate the loss of tree diversity-dependent productivity $(\Delta P)$ from 2005 to 2070 s. The effect sizes [inverse of $\log ($ mitigation/baseline $)]$ of $\Delta \mathrm{P}$ were estimated at the local scale (at the 30 arcseconds; the total number of grids $=\sim 115$ million for each scenario). The effect size is shown as a log ratio scale; zero corresponds to the true absence of the outcome. Positive and negative values of effect size indicate more and less effectiveness of mitigation policy, respectively (green and red arrows, respectively). All points indicate mean effect size. Results are shown for the five Shared Socioeconomic Pathways (SSPs) and the three General Circulation Models (GCMs). See Supplementary Data 3 for the values of means and the associated $95 \%$ confidence intervals of the effect sizes. 

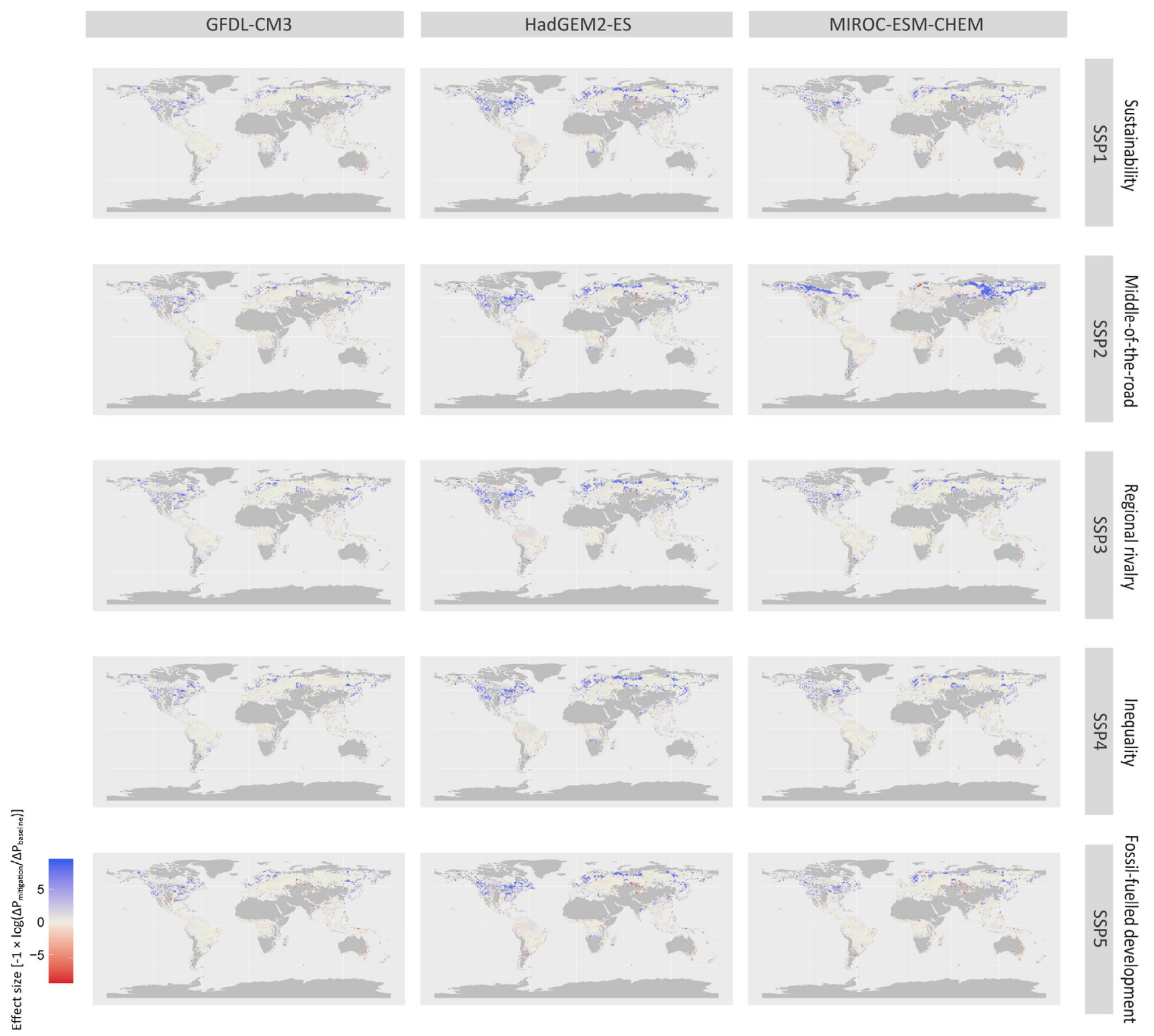

Extended Data Figure 5. Maps showing the effects of a climate change mitigation to alleviate the loss of tree diversity-dependent productivity $(\Delta P)$ from 2005 to 2070s. The effect sizes [inverse of $\log ($ mitigation/baseline)] of $\Delta \mathrm{P}$ were estimated at the local scale (at the 30 arcseconds; the total number of fine grids $\sim 115$ million for each scenario). Positive and negative values of effect size indicate more and less effectiveness of mitigation policy, respectively. In these maps, means of the effect sizes within each of the coarse grids ( $n=32,670$ coarse grids) are shown. Results are shown for the five Shared Socioeconomic Pathways (SSPs) and the three General Circulation Models (GCMs). Files to produce these maps are provided as Supplementary Data 4. 


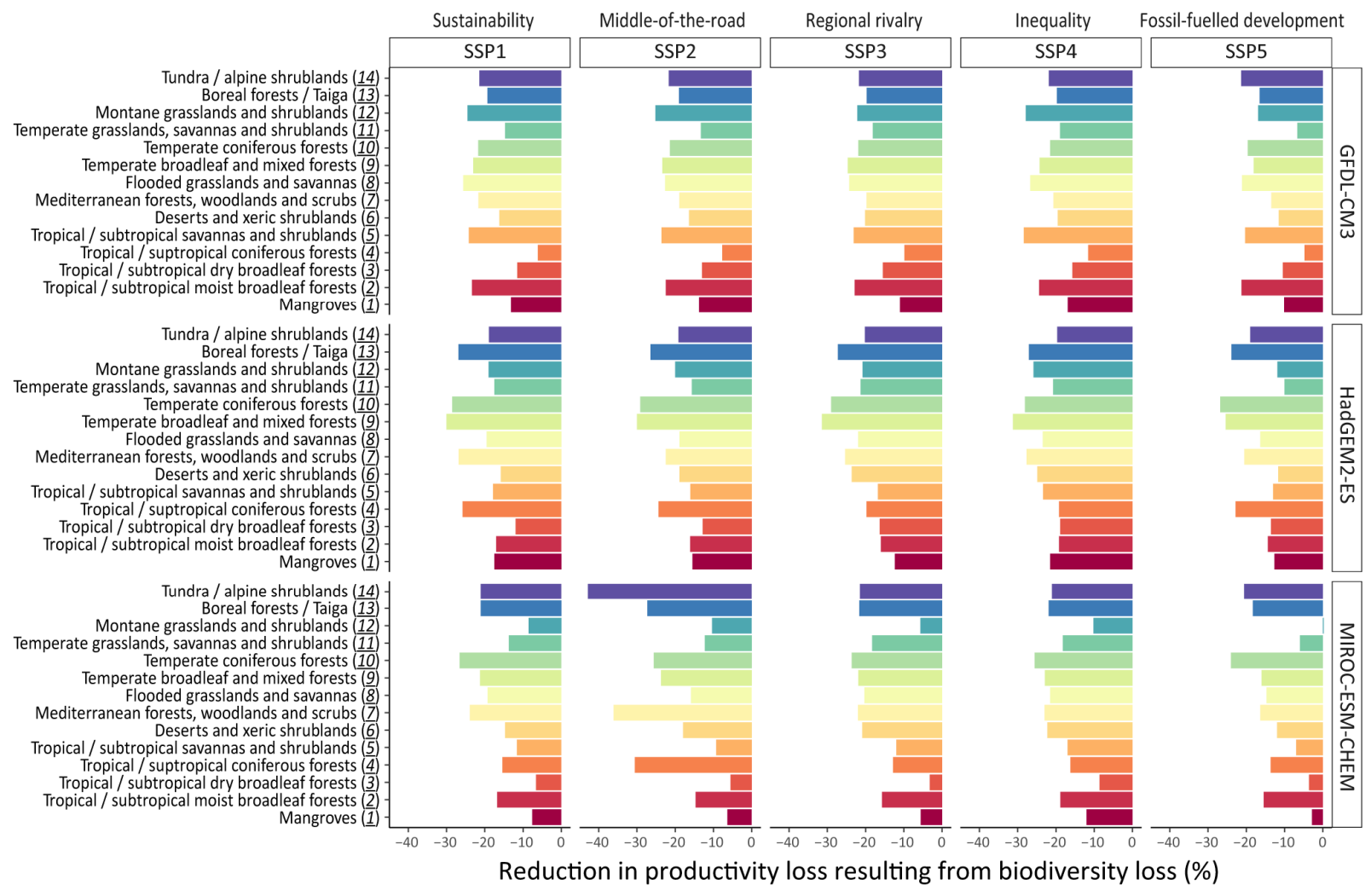

Extended Data Figure 6. Biome-level sums in alleviating the loss of tree diversity-dependent productivity ( $\Delta \mathrm{P})$ from 2005 to 2070s. Proportional reductions (\%) in $\Delta \mathrm{P}$ are summarised for each of 14 different biomes. Negative values indicate the relative magnitude of reduction in productivity loss by the implementation of additional climate mitigation policy compared to the estimates based on business-as-usual scenario. Results are shown for the five Shared Socioeconomic Pathways (SSPs) and the three General Circulation Models (GCMs). 


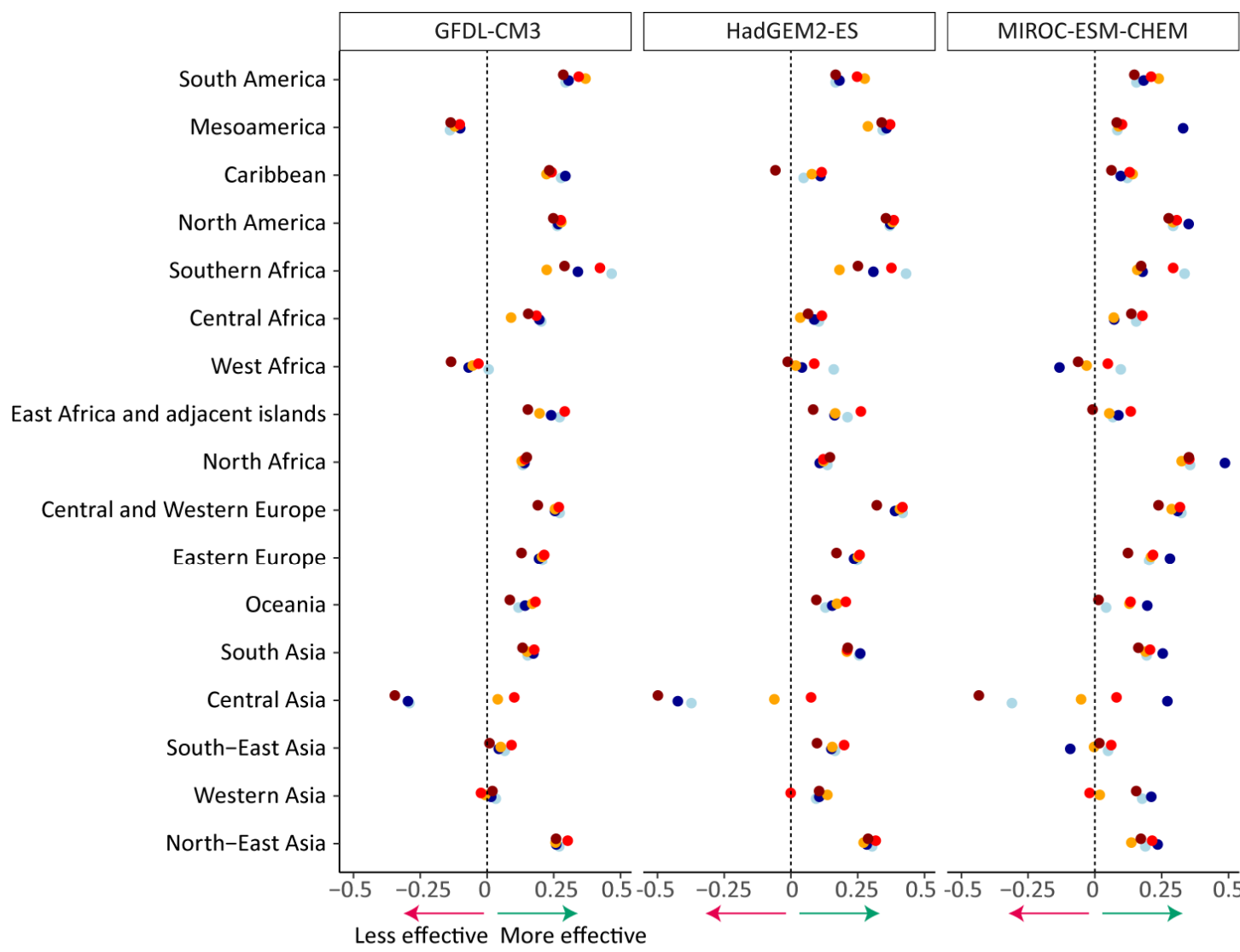

Effectiveness to alleviate productivity loss $\left[-1 \times \log \left(\Delta \mathrm{P}_{\text {mitigation }} / \Delta \mathrm{P}_{\text {baseline }}\right)\right]$

\begin{tabular}{|c|c|c|c|c|}
\hline$\rightarrow$ SSP1 & $\rightarrow$ SSP2 & $\rightarrow$ SSP3 & $\rightarrow$ SSP4 & $\rightarrow$ SSP5 \\
\hline Sustainability & Middle-of-the-road & Regional rivalry & Inequality & Fossil-fuelled development \\
\hline
\end{tabular}

Extended Data Figure 7. Subregion-level projections in the effects of a climate change mitigation to alleviate the loss of tree diversity-dependent productivity $(\Delta P)$ from 2005 to $2070 \mathrm{~s}$. The effect sizes [inverse of $\log$ (mitigation/baseline)] of $\Delta \mathrm{P}$ were estimated at the local scale (at the 30 arcseconds; the total number of grids $=\sim 115$ million for each scenario). The effect size is shown as a $\log$ ratio scale; zero corresponds to the true absence of the outcome. Positive and negative values of effect size indicate more and less effectiveness of mitigation policy, respectively (green and red arrows, respectively). The points indicate means. Subregions are based on the Intergovernmental Science-Policy Platform on Biodiversity and Ecosystem Services; IPBES ${ }^{1}$ ). Results are shown for the five Shared Socioeconomic Pathways (SSPs) and the three General Circulation Models (GCMs). See Supplementary Data 5 for the values of means and the associated $95 \%$ confidence intervals of the effect sizes. 


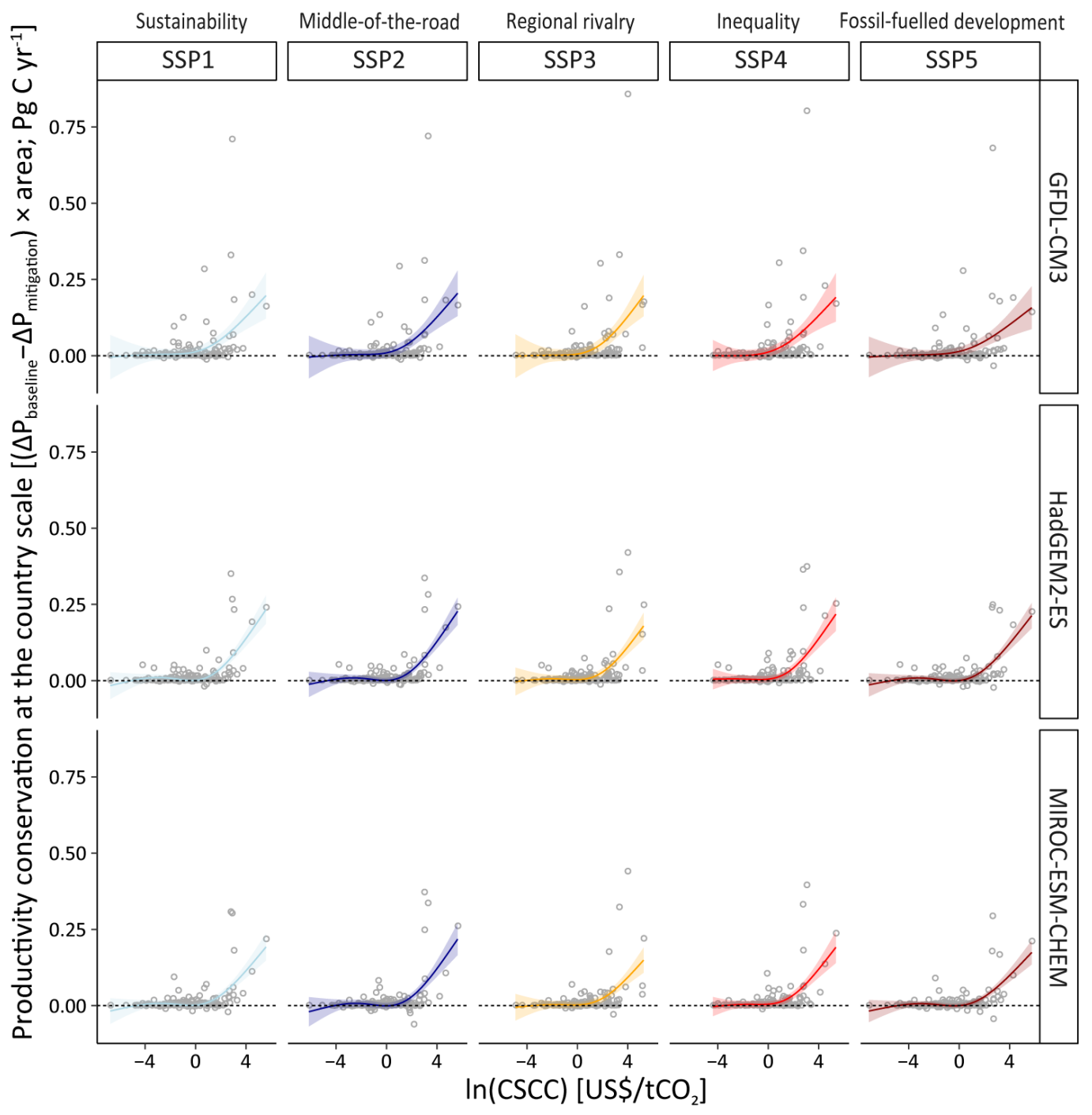

Extended Data Figure 8. The relationships between the country-level social cost of carbon $\left(\mathrm{CSCC}^{2}\right)$ and the country-level conservation of tree diversity-dependent productivity $(\Delta \mathrm{P})$. The lines and shaded areas are the estimates based on a generalized additive mixed model and their $95 \%$ confidence intervals, respectively. Results are shown for the five Shared Socioeconomic Pathways (SSPs) and the three General Circulation Models (GCMs). See Supplementary Data 6 for the values of means and the associated $95 \%$ confidence intervals of the effect sizes [inverse of $\log ($ mitigation/baseline $)]$ of climate change mitigation policy to alleviate the loss of tree diversitydependent productivity for each country. 


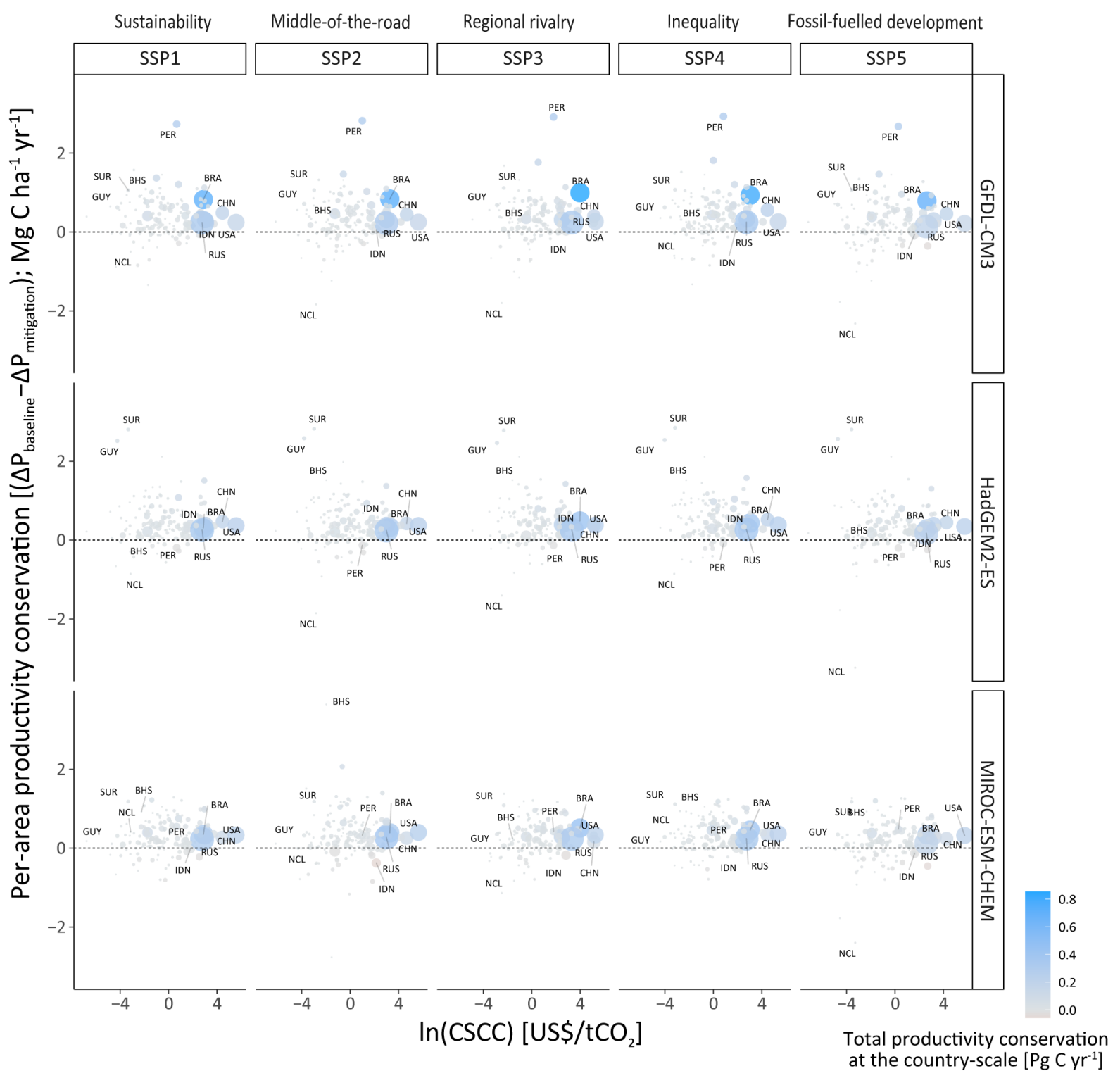

Extended Data Figure 9. The relationships between the country-level social cost of carbon $\left(\mathrm{CSCC}^{2}\right)$ and the country-level per-area conservation of tree diversity-dependent productivity $(\Delta \mathbf{P})$. The size of circles is proportional to the forested area of each country. The colors of circles correspond to the country-level sum of productivity conservation shown in Extended Data Figure 8 (see the color scale at the bottom right). Results are shown for the five Shared Socioeconomic Pathways (SSPs) and the three General Circulation Models (GCMs). Names of major and outlier countries are shown beside the symbols; ISO 3166-1 alpha-3 code is used to indicate countries. 


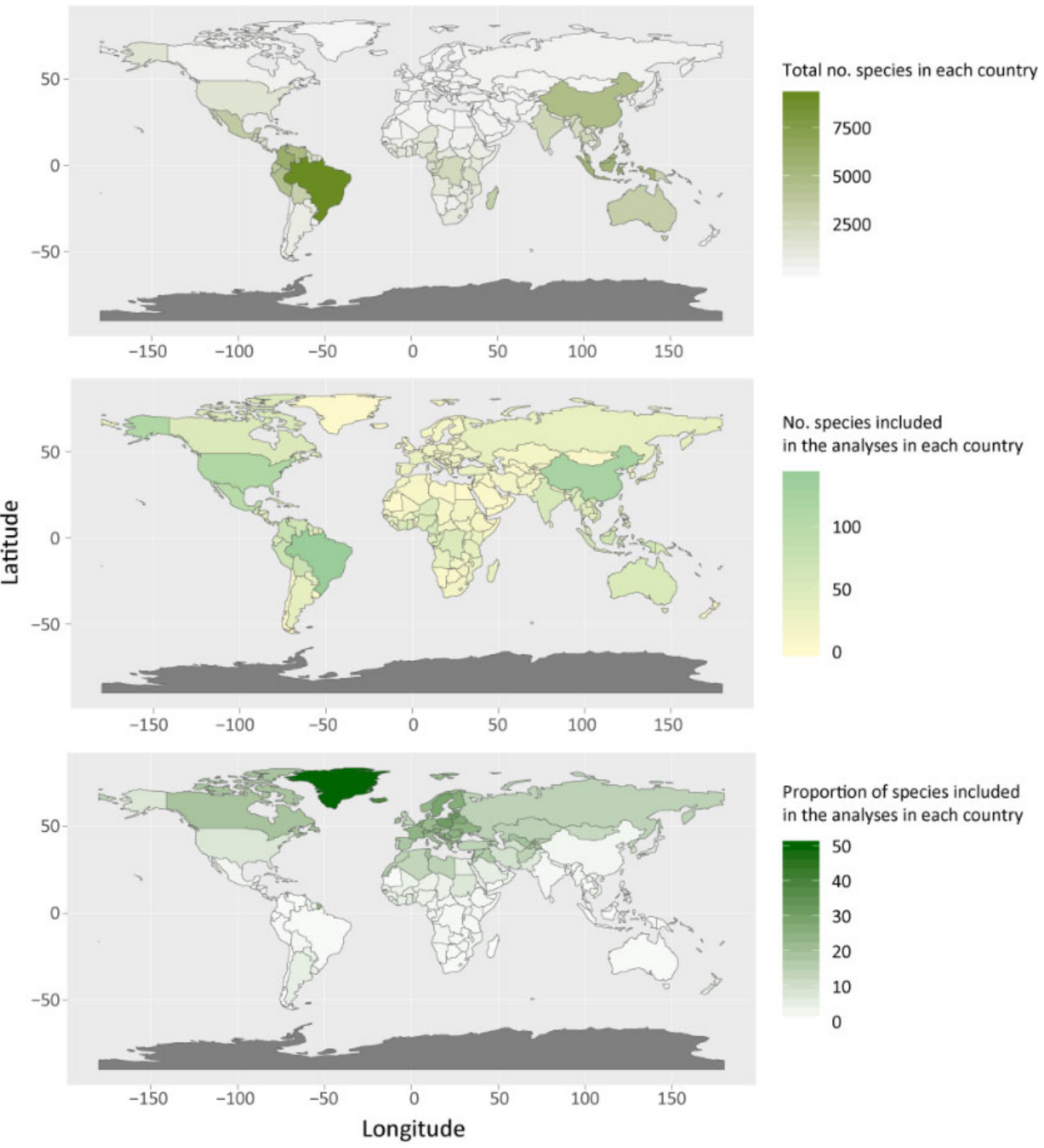

Extended Data Figure 10. Tree species analysed. The maps showing the total number of tree species reported in each country ${ }^{3}$, and the number of the target species (those analysed in the present study) and the proportion (\%) of these target species within the total number of species reported in each country ${ }^{3}$. 


\section{References}

1 IPBES. Summary for policymakers of the global assessment report on biodiversity and ecosystem services of the Intergovernmental Science-Policy Platform on Biodiversity and Ecosystem Services. (2019).

2 Ricke, K., Drouet, L., Caldeira, K. \& Tavoni, M. Country-level social cost of carbon. Nat Clim Change 8, 895-900, doi:10.1038/s41558-018-0282-y (2018).

3 BGCI. Global Tree Search Database (Botanic Gardens Conservation International, 2019). 


\section{Supplementary Information}

Biodiversity-productivity relationships are key to nature-based climate solutions

Mori et al.

This PDF file includes:

Supplementary Table 1-2

Supplementary Figure 1-6

Other Supplementary materials for this manuscript include the following:

Extended Data Figure 1-10

Supplementary Data 1-6 


\section{METHODS}

Supplementary Figure 1 and 2 are the schematic diagrams for workflow how we estimated proportional changes in species richness and forest productivity and absolute changes in net primary productivity at the local scale.

\section{Species distribution modelling}

Spatially-explicit observations of tree species were from the previous study ${ }^{1}$. We provide a protocol for our species distribution model [Overview, Data, Model, Assessment and Prediction (ODMAP) protocol'; Supplementary Table 1]. Briefly, we obtained all records of trees and shrubs (hereafter, referred to as trees) from the Global Biodiversity Information Facility (doi.org/10.15468/d1.8u65om; as of July $22^{\text {nd }} 2015$ ), and then filtered out records with geographic location by referring to the database of Global Administrative Areas (www.gadm.org; as of August $\left.3^{\text {rd }} 2015\right)^{3}$. To discard locations where species have been introduced, we excluded records from outside of their native ranges by referring to the Red List of Threatened Species (www.iucnredlist.org). Native ranges were determined by presence/absence in 12 land regions: North America, Mesoamerica, Caribbean Islands, South America, Europe, North Africa, Sub-Saharan, North Asia, West and Central Asia, East Asia, South and Southeast Asia, and Oceania. The Antarctic was excluded from the analysis. Note that, in the previous study ${ }^{1}$, species distribution modelling was conducted at a spatial resolution of 30 arcminutes (hereafter, coarse grids). Here we extended the modelling to a resolution of 30 arcseconds (hereafter, fine grids) to improve our approximation of biodiversity-dependent productivity (see the section, Species richness and productivity estimation). However, the modelling for species distributions at the fine-scale was only possible for the present period, because our models relied on land-use and climatic variables and future land-use variables were only available at the scale of coarse grids. We sampled one occurrence record per grid for all species at both spatial resolutions. To avoid the effect of model inaccuracy from a small sample size, we limited our analysis to species that had 30 and more refined occurrence records ${ }^{4}$. These resulted in 1,755 and 934 target tree species at a spatial resolution of fine and coarse grids, respectively. Note that we coped with uncertainties due to the difference in the number of target species between the two periods by combining spatially explicit simulations and machine learning regressions (described later).

For the present period, we obtained a dataset of 19 bioclimatic variables, calculated from the monthly minimum temperature, maximum temperature, and precipitation at a resolution of fine grids

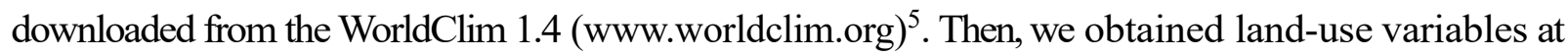
a resolution of fine grids from the MODIS (Moderate resolution Imaging Spectroradiometer) Land Cover Type for the year 2005 (glcf.umd.edu/data/lc). We used land cover classes of the global vegetation 
classification scheme of the International Geosphere-Biosphere Programme (www.igbp.net) as a categorical variable in our models of species distribution. One of the five land-use types (cropland, pasture, forest, other natural lands, and settled land) was assigned to each of the fine grids. If several pixels with different land cover types were included in a fine grid, one with the largest area was assigned as the representative land cover type.

For future scenarios, we focused on mitigation and high-emission baseline scenario based on representative concentration pathways (RCPs): the mitigation scenario aimed to stabilize climate change at the end of the 21 st century, whereas the baseline scenario assumed increasing greenhouse gas (GHG) emissions and thus climate change over time ${ }^{1}$. We set the target years as the $2070 \mathrm{~s}$, the latest period in the Worldclim 1.4 projections. We used future climatic variables based on the General Circulation Models (GCMs) included in the Fifth Coupled Model Inter-Comparison Project (CMIP5) experiment: MIROC-ESM-CHEM ${ }^{6}$, HadGEM2-ES ${ }^{7,8}$, and GFDL-CM3 ${ }^{9}$, downloaded from WorldClim ${ }^{5}$. All 19 bioclimatic variables for the future were calculated by using the same method as for the current climate. We aggregated the climatic variables to obtain mean values at the coarse resolution. Future land-use changes under the mitigation and baseline scenarios ${ }^{10}$ were based on the $\mathrm{AIM} / \mathrm{CGE}^{11}$, a computable general equilibrium model representing the entire global economy. The AIM/CGE implements climate change mitigation in the form of a global uniform carbon tax on GHG emissions from the agriculture, land-use, and energy sectors. In the model, supply, demand, investment, and trade are described by individual behavioural functions that respond to changes in the prices of production factors and commodities, as well as changes in technology and preference parameters on the basis of assumed population, gross domestic production, and consumer preferences. The allocation of land by sector for 17 regions is formulated as a multinomial logit function to reflect differences in substitutability across land rent, and regional land use is further downscaled to high spatial resolution with the AIM/PLUM downscaling model ${ }^{12}$ based on spatially explicit attainable yields. In this study, we used future land-use variables ${ }^{10}$, which were based on the Shared Socioeconomic Pathways (SSPs) framework ${ }^{13}$. The SSPs are based on five narratives describing how socioeconomic factors may change over the next century, considering changes in population, GDP, energy, emissions, and land use. We relied on the five SSPs: challenges to adaptation and mitigation are both low (SSP1: sustainability) or both high (SSP3: regional rivalry); low challenges to mitigation are combined with high challenges to adaptation (SSP4: inequality); high challenges to mitigation are combined with low challenges to adaptation (SSP5: fossil-fuelled development); intermediate challenges exist for both adaptation and mitigation (SSP2: middle-of-the-road). For instance, the SSP1 and SSP4 assume low fossil fuel dependence and increased deployment of non-fossil energy sources, leading to lower greenhouse gas emissions. Energy demand is the lowest in the SSP1 scenario peaking around the middle of the $21^{\text {st }}$ century and declining thereafter due to energy efficiency measures and behavioral changes ${ }^{13}$. See Supplementary Table 2 for further details. The SSPs employ a concept called scenario matrix 
architecture, which has a two-dimensional space comprising socioeconomic patterns and climate mitigation levels defined by radiative concentration pathways (RCP). For our mitigation scenarios, we used each SSP, combined with the RCP with the lowest radiative forcing level. SSPs 1, 2, 4, and 5 were combined with RCP 2.6. SSP3 was combined with RCP3.4 because the SSP3-RCP2.6 combination was found to be incompatible due to high levels of energy intensity ${ }^{13,14}$. We used the high-emission baseline condition in each SSP for the baseline scenario, assuming the absence of additional climate policy and efforts. For instance, baseline scenarios of the SSP3 and SSP5 have a heavy reliance on fossil fuels with an increasing contribution of coal to the energy mix; the challenges for mitigation are thus high ${ }^{13}$. Given that land-use scenarios explicitly incorporated areas for bioenergy crops and afforestation for GHG mitigation activity, which did not exist in land-use data in the current condition, bioenergy crops and afforestation were merged into cropland and forests, respectively.

As described in the previous work ${ }^{1}$. we employed MaxEnt v3.3 $3^{15}$, a modelling approach that works well for cases in which only presence data are available and absence data are difficult to collect ${ }^{16}$, for predicting the current and future probability of occurrence of target species. To incorporate sampling bias into MaxEnt, we took the bias background approach, which uses the prior information on the spatial distribution of survey effort to preselect background locations before running MaxEnt. In this approach, the effect of sampling bias cancels out because it is common to both occurrence and background. To do this, we combined all occurrence records in the final dataset for target taxonomic groups (including species with $<30$ records) and generated a set of background data, weighted by the sampling density of occurrence records. The number of background data was determined as $20 \%$ of grids that contained occurrence records of the target taxonomic group. In the model development procedure, the background data were extracted within the native range for each species. We identified a species-specific set of explanatory variables for each of the target species. First, by using the five land-use and 19 bioclimatic variables, we generated all possible combinations of these explanatory variables. We then excluded explanatory variables showing collinearity. We selected the most parsimonious combination of explanatory variables based on the corrected Akaike information criterion (AICc) ${ }^{17}$. MaxEnt is capable of building complex nonlinear functions of explanatory variables by combining simple mathematical transformations of explanatory variables, or so-called features ${ }^{18}$; it selects the features for each explanatory variable that contribute most to model fit using regularization. We tested 31 regularization coefficients (from 0 to 15 at increments of 0.5 ) and chose the one for each species that maximized model fit under the given combination of explanatory variables selected, based on $\mathrm{AICc}^{19}$. Among the final models developed for all species, we discarded those with poor performance for subsequent analyses based on 10-fold cross validation, as follows. We assessed model performance using the continuous Boyce index (CBI), which is used to evaluate model quality for predictions based on presence-only data ${ }^{20}$. This index varies between -1 and 1 ; negative values indicate an incorrect model, values close to 0 mean a chance model, and positive values indicate a model whose predictions are consistent with the presence distribution in the test set. We 
used models with CBI $>0$ based on the $95 \%$ confidence interval for the subsequent analyses. To obtain a map of suitable habitat for each species under the current conditions, the average value of the relative probability of occurrence calculated by the 10 -fold cross-validation was converted into a binary map. We applied the average of the $90 \%$ sensitivity threshold to minimize the falsenegative fractions and to avoid underestimating the suitable habitat $\operatorname{area}^{21}$. For the future scenarios, a species' ability to disperse and track the shifting climate, a crucial determinant of future potential for range shifts ${ }^{22,23}$, was explicitly considered ${ }^{1}$. Because dispersal ability is strongly related to life-history traits $^{23}$, we collected information on life-history traits for all target species and estimated dispersal distance for each species by the 2070s. Here dispersal distance per generation was estimated from the formula based on an earlier work ${ }^{23}$; we adopted 'group 5' formula in dispeRsal function, which requires species-specific data for dispersal syndrome and growth form. For dispersal syndrome, we compiled the database from various sources (details are found in the Source Data of the earlier study ${ }^{1}$ ). For growth form, we obtained the data from a database of The IUCN Red List of Threatened Species (www.iucnredlist.org). Generation length was estimated according to growth form ${ }^{24}$. Based on the above estimates, we obtained habitat maps for individual species. The possible changes in areas hospitable to species under different future scenarios are described in the earlier work ${ }^{1}$ : briefly, the losses of suitable habitats due to the combined effects of climate and land-use were estimated to be smaller in the mitigation scenario than in the baseline scenario (e.g., approximately $17-28 \%$ and $22-36 \%$ for the mitigation and baseline scenario, respectively, across a wide range of organism groups).

\section{Species richness and productivity estimation}

For the calculations below, we have mainly relied on "vegan"25 " mobsim"26, and "xgboost"27 package of the R software ${ }^{28}$. We projected spatial distributions of individual species for the year 2005 and 2070s at the spatial resolution of 30 arcminutes (coarse grids; $n=32,670$ ). For both periods, we obtained the total number of species present in each coarse grid (hereafter, $\gamma$-diversity). For the former year, we also projected spatial distributions of individual species at the spatial resolution of 30 arcseconds (fine grids; $\mathrm{n}=115,426,714$ ). Based on these projections, we calculated changes in species richness at the scale of fine grids (hereafter, $\alpha$-diversity) from 2005 to 2070s for different scenarios of climate and land-use changes. The reason why we conducted this downscaling was that there could be a potential mismatch due to scaling issues ${ }^{29,30}$. That is, changes in $\gamma$-diversity are not universally proportional to those in $\alpha$-diversity across different coarse grains. Furthermore, we relied on the values of the elasticity of substitution $(\theta)$ of a previous study ${ }^{31}$. Although assumed to be scaleindependent, these estimates were developed based on the forest inventory dataset collected at the local spatial scale. We thus aimed to estimate the changes in productivity at this fine-scale. Here, we first obtained species-area and endemics-area relationships (SARs and EARs, respectively) for the year 2005 that were unique to each of the coarse grids; 50 sub-grids were randomly chosen with $1 \%$ intervals between the scales of the fine and coarse grid to construct the curves ${ }^{26}$. If all fine grids were 
forested, a coarse grid had 3,600 fine grids. These relationships were used to estimate $\alpha$-diversity in the year 2005. Note that it was infeasible to directly estimate the temporal changes in $\gamma$-diversity because future spatial distributions were estimated only for a subset of species present in the 2005 data (i.e., widespread common species) as described earlier. Instead, we used the number of these common species that went extinct from or immigrated into a given coarse grid by the 2070s for estimating the number of other subordinate species (that were excluded in the MaxEnt analysis for the period of 2070s because of limited occurrence at the scale of 30 arcminutes; see the section for species distribution modelling) that went co-extinct or co-immigrated ${ }^{32,33}$.

To realize this, we first implemented two spatially explicit simulations for species coextinction and co-immigration. In an artificial landscape with 3,600 homogeneous grids, we randomly draw between 5 and 80 species with total occurrence between 500 and 180,000 individuals, based on a lognormal species abundance distribution (SAD) with randomly assigned parameters $\mu$ and $\sigma$ of SADs reported in different biomes ${ }^{34-36}$. We used large ranges of parameters (the number of species and individuals) because of many possibilities in different biomes from tropics to northern woodlands (e.g., 5 species as a minimum is to represent the size of species pool in hemiboreal, boreal, and taiga landscapes). To consider many possibilities of spatial patterns of tree individuals in different biomes, we randomly assigned individuals of each species to each of the 3,600 grids. For each of these artificial meta-communities, we calculated mean $\alpha$-diversity (number of species per grid), $\gamma$-diversity (number of species per landscape), Whittaker's multiplicative $\beta$-diversity, and Shannon's evenness (across the grids) $)^{36,37}$. We also constructed SARs for estimating species richness at the smallest spatial scale. Here we defined common species as abundant species that had an abundance rank of $25 \%$ or below; that is, in each simulation run, we randomly assigned species with the dominance rank between 1 and the upper quartile as common species. For co-extinction simulation, we randomly made some of (up to half of) these common species extinct from a meta-community. Other rare species that were present in the same grid with these extinct common species were also forced to extinction, assuming that these grids became no longer habitable for any species because of possible climate and land-use change. Note that, in reality, species extinction can occur spatially in a non-random fashion and the consequences for ecosystem functioning may differ between random and non-random loss of species ${ }^{38}$. However, because substantial uncertainty exists as to land use patterns in different regions ${ }^{39}$, we randomly made some species go extinct so as to cover many possible extinction scenarios; we emphasize that such random extinction was for species identity and not for locations (that is, not assuming random land clearing). That is, based on which species are lost, the locations of these species previously present are cleared. Furthermore, the choice of the extinction limit (up to half of the common species could be lost) was to have a conservative estimate. For coimmigration simulation, we assumed that an artificial meta-community resulted from additional immigration of both common and rare species. We again randomly assigned some of (up to half) the species as common and removed them from the meta-community to construct a pre-immigration 
meta-community. We also removed individuals of other species that were present in the same grid with these common species, assuming that these grids became newly hospitable in a post-immigration meta-community. We repeated the above co-extinction and co-immigration simulations 25,000 times, respectively. From that, we had an estimate of how many rare species could be co-extinct or coimmigrated with common species in these simulated meta-communities. Then we used a method of extreme gradient boosting (XGBoost) ${ }^{27}$ to obtain machine learning regressions for predicting the number of species co-extinct and co-immigrated based on other information described above (different diversity metrics explained above, parameters of SAD, total frequency occurrence of existing species, and the number of common species extinct or immigrated). We assigned 5,000 and 20,000 results of the simulation runs for evaluation and training, respectively. The best regressions were obtained using a 10-fold cross validation (tested with the root mean square error performance metric). Overall, the regressions for predicting the number of species co-extinct/co-immigrated showed reasonable goodness of fit $\left(R^{2}=0.802\right.$ and 0.593 for species co-extinction and coimmigration, respectively).

We applied these regressions to results of species distribution modelling (also see Supplementary Fig. 2 for a schematic diagram). By comparing the number of widespread common species in each coarse grid between the year of 2005 and 2070s, we obtained the number of common species extinct or immigrated. By combining this information with the same set of information required for our XGBoost regressions, all of which were obtained from the 2005 data for each of the 32,677 coarse grids, we regressed the potential number of subordinate species co-extinct and coimmigrated. These regressions allowed us to predict potential $\gamma$-diversity for the period of $2070 \mathrm{~s}$ in each of the coarse grids. When we observed extinctions of some species for the 2070s in a given coarse grid, we converted this total number of species lost into a proportion of habitats that was required for losing these species based on the unique $\mathrm{EAR}^{40}$. When we observed immigration by some species for the 2070s in a coarse grid, then we converted this total number of species gained into a proportion of habitat that was required to gain these species based on the unique $\mathrm{SAR}^{40}$. By multiplying these proportional changes in the habitable areas for the period of 2070s with species richness values at the scale of fine grids, which were expected from the unique SARs in the year 2005, we obtained the values of $\alpha$-diversity in the 2070s. In some coarse grids, it was not possible to obtain unique SARs or EARs for reasons such as low $\gamma$-diversity in northern biomes. In such a case, we assumed that proportional changes in the habitable areas between the two periods were estimated by relying on an empirical SAR with the slope value of 0.3 in log-log space ${ }^{41,42}$. Based on the changes in $\gamma$-diversity, we estimated the values of $\alpha$-diversity in the 2070s. Note that, likewise the year of 2005 , each of the coarse grids in the period of 2070 s also had a single unique value of $\alpha$-diversity ( $n=$ $32,670)$.

We calculated proportional changes in $\alpha$-diversity from the year of 2005 to the period of 2070s (\%), and converted them into proportional changes in forest productivity (\%) based on 
parameters of the elasticity of substitution $(\theta)$, which were estimated for forest biomes worldwide with a spatial resolution of the coarse grids ${ }^{31}$; the elasticity of substitution can be used to estimate forest productivity based on proportional changes in species richness of tree species (i.e., $\alpha$-diversity). More specifically, the $\theta$ values represent the marginal productivity - the change in productivity resulting from the one-unit decline of species richness after accounting for climatic and soil covariates. The $\theta$ values were estimated across the forested biomes worldwide ${ }^{31}$, ranging between 0.198 and 0.299; a global mean was estimated as 0.26 with a standard deviation of 0.09 . Note that $0<\theta<1$ represents a positive and degressively increasing curve of richness-productivity relationships. The $\theta$ values were estimated based on tree volume productivity $\left(\mathrm{m}^{3} \mathrm{ha}^{-1} \mathrm{yr}^{-1}\right)$ in terms of periodic annual increment, calculated from the sum of individual tree stem volume $\left(\mathrm{m}^{3}\right)^{31}$. The values of the elasticity of substitution were originally estimated based on the forest inventory dataset collected at the local spatial scale $^{31}$. For avoiding a potential mismatch due to scaling issues ${ }^{29,30}$, we estimated the changes in productivity at the scale of fine grids. We used a net primary productivity (NPP) dataset estimated using the MODIS imagery ${ }^{43}$ for the year 2005. In the terrestrial biomes analysed here, the total NPP

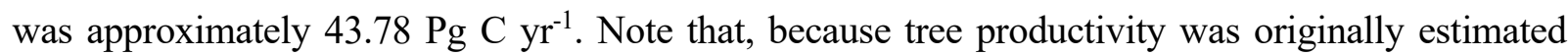
based on an increment in stem volume of individual trees, the estimated proportional changes in forest productivity cannot fully capture NPP of terrestrial vegetation; however, a substantial fraction of primary productivity in forested biomes is derived from tree growth. We obtained NPP values at the scale of fine grids. Here we assumed that all fine grids in a given coarse grid showed the equivalent changes in productivity in a proportional scale, reflecting the mean change in $\alpha$-diversity expected to occur in that coarse grid. Based on these estimations, we have obtained absolute changes in forest productivity $\left(\mathrm{kg} \mathrm{C} \mathrm{m}^{-2} \mathrm{yr}^{-1}\right)$ for different scenarios of climate/land-use changes at the scale of fine grids. Our analyses for tree diversity and productivity changes were conducted for the grids, where tree species were observed and the $\theta$ values were available; thus, the results are also shown for nonforested biomes.

\section{Data analyses}

We primarily relied on "maptools" $44, s f$ "45, and "tidyverse" summarizing our estimates. Within the forested areas analysed in the previous study ${ }^{31}$, we summarized our results at different spatial scales from local to the globe. Here, the fine grids are defined as the local scale. We also focused on the scales of countries and biomes. Terrestrial biome categories are based on the 14 terrestrial ecoregions used in World Wildlife Fund (www.worldwildlife.org). We have obtained information for areas and names of individual countries from Natural Earth (www.naturalearthdata.com; as of August $1^{\text {st }}, 2019$ ), which primarily follows the setup of the United Nations Statistics Division (unstats.un.org; as of August $1^{\text {st }}, 2019$ ). To be relevant to the global policy, we have summarized results also at the scale of the subregion used in the Intergovernmental Science-Policy Platform on Biodiversity and Ecosystem Services (IPBES; 
www.ipbes.net/deliverables/2b-regional-assessments). For some territories and nations that are not explicitly classified into regional categories, we assigned their subregions based on their geographical locations.

To quantify the effect sizes of mitigation efforts on conservation of species and productivity, we calculated the reductions in local-scale loss of species $(\Delta \mathrm{SR})$ and productivity $(\Delta \mathrm{P})$ as a log ratio scale, which assumes that zero corresponds to the true absence of the outcome (i.e., no difference between the two scenarios). Estimates based on the baseline and mitigation scenarios were used for the denominator (control; $\Delta \mathrm{SR}$ baseline and $\Delta \mathrm{P}_{\text {baseline}}$ ) and numerator (treatment; $\Delta \mathrm{SR}_{\text {mitigation }}$ and $\Delta \mathrm{P}_{\text {mitigation}), \text { respectively. We used "ARPobservation" }}{ }^{47}$ package of the $\mathrm{R}$ software ${ }^{28}$ to obtain logresponse ratios and the associated $95 \%$ confidence intervals for each of the combinations of SSP scenarios and GCMs. To facilitate interpretation, we multiplied -1 with the effect sizes and thereby positive and negative values, respectively, indicate more and less effectiveness of climate mitigation policy in reducing species loss and the associated productivity loss (also see a schematic diagram in Supplementary Fig. 3). We confirmed that spatial patterns of the effect size of productivity responses were not driven by those of the $\theta$ values; $R^{2}$ values of linear regressions ranged between 0.0005 and 0.016 across all combinations of GCMs and SSPs. To ensemble results across the three GCMs, we adopted a meta-analytical approach; we used "metafor" 48 package to obtain global means and the associated $95 \%$ confidence intervals for each SSP scenario. We repeated the above calculations at the biome- and IPBES subregion-, and country-scale. For biome-level analyses, we used the same package for a mixed-effects meta-regression with the effect size as a response variable, the GCMs as a random effect, and climate conditions (mean annual temperature or precipitation of biomes) as a moderator. We additionally provide maps showing the mean and variability among the GCMs in predicting tree diversity and associated productivity changes in Supplementary Figure 4-6.

Then, we focused on the relationship between the country-level social cost of carbon [CSCC (US\$ $\mathrm{tCO}_{2}{ }^{-1}$ ); the Burke-Hsiang-Miguel damage function ${ }^{49}$, estimated for each of SSPs] and the country-level reduction in forest productivity loss under a given SSP. Here we were interested in the country-level loss of productivity (absolute changes within each country), instead of the productivity loss per area that can give the average estimates of local productivity changes within a focal area (e.g., proportional changes within each country). We thus summed up the differences between the $\Delta \mathrm{P}_{\text {baseline }}$

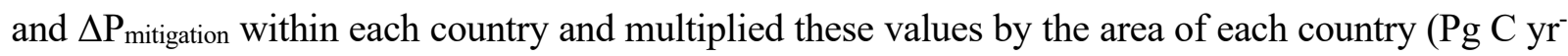
$\left.{ }^{1}\right)$. The country areas were obtained by summing up areas of the fine grids analysed for the changes in biodiversity and productivity, by considering the changes in fine grid area $\left(\mathrm{m}^{2}\right)$ along a latitudinal gradient. This gave us the sums of reduction in productivity loss at the country level, which was used as a response variable in our models. For each of the individual combinations of SSPs and GCMs, we relied on a generalized additive model (GAM) with the CSCC as an explanatory variable. To ensemble results across the GCMs, we used a generalized additive mixed model (GAMM) with the GCMs as a random effect and the CSCC as an explanatory variable. We additionally checked if the 
results were affected by land area, using the GAMMs.

Lastly, we summed up the reduction in productivity loss across all countries, under each of SSPs and GCMs. This gave us the estimate of global productivity conservation, corresponding to the value, global $\sum\left(\Delta \mathrm{P}_{\text {baseline }}-\Delta \mathrm{P}_{\text {mitigation }}\right)$ (Fig. $\left.6 \mathrm{~d}\right)$. Caution is necessary to interpret the results. For instance, although the values of global productivity conservation were similar between SSP1 and SSP3 (Fig. 6d), these SSPs are based on contrasting assumptions including those about deforestation and reforestation/afforestation ${ }^{10,13,14}$. While substantial reforestation is expected in the SSP1 mitigation scenario, the expansion of bioenergy crops at the expense of forest area is assumed to occur in the SSP3 mitigation scenario. Also, little and large shrink of forest areas is expected for the SSP1 and SSP3 baseline scenario, respectively. Likely reflecting these contrasts, global $\Delta \mathrm{P}_{\text {baseline }}$ and

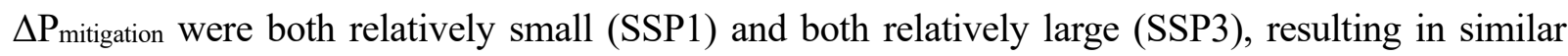
values of productivity conservation. Likewise, our estimations were primarily based on a comparison between the baseline and mitigation scenarios.

Data availability The source data underlying figures (Supplementary Data 1-6) are archived in the Dryad repository: https://doi.org/10.5061/dryad.vq83bk3s2.

Code availability The code that support the findings of this study are available from the corresponding author upon reasonable request. 
Supplementary Table 1.

\begin{tabular}{|c|c|}
\hline ODMAP element & Contents \\
\hline \multicolumn{2}{|l|}{ Overview } \\
\hline Model objective & $\begin{array}{ll}\text { - } & \text { Objective: Transfer/Forecast } \\
\text { - } & \text { Target outputs: Map of potential suitable habitat }\end{array}$ \\
\hline Taxon & Woody vascular plant species \\
\hline Location & Global \\
\hline Scale of analysis & $\begin{array}{l}\text { - Spatial extent (Lon/Lat): Longitude } 180^{\circ} \mathrm{W}-180^{\circ} \mathrm{E} \text {, Latitude } 60^{\circ} \mathrm{S}-84^{\circ} \mathrm{N} \\
\text { - } \\
\text { - } \\
\text { Tpatial resolution: } 30 \text { arcminutes (coarse-scale), } 30 \text { arcseconds (fine-scale) } \\
\text { data was based on the average of } 1960-1990 \text {. Land use data was based on } \\
2005 . \\
\text { - Type of extent boundary: Rectangular }\end{array}$ \\
\hline Biodiversity data overview & $\begin{array}{l}\text { - Observation type: Occurrence record from various sources including human } \\
\text { observation, machine observation, and specimen collection records. } \\
\text { - } \quad \text { Response/Data type: Presence-only }\end{array}$ \\
\hline Type of predictors & Climatic, land-use \\
\hline $\begin{array}{l}\text { Conceptual model/ } \\
\text { Hypotheses }\end{array}$ & $\begin{array}{l}\text { Hypotheses: We used climate (annual trends, seasonality, and extreme or limiting } \\
\text { factors) and land-use as important environmental predictor variables for tree and } \\
\text { shrub species on the global scale. }\end{array}$ \\
\hline Assumptions & $\begin{array}{l}\text { Relevant ecological drivers (or proxies) of species distributions are included. } \\
\text { Species are at equilibrium with their environment. }\end{array}$ \\
\hline SDM algorithms & $\begin{array}{l}\text { - Algorithms: We fitted MaxEnt }{ }^{15} \text { to occurrence data. MaxEnt was chosen due } \\
\text { to competitive performance on a small sample size and presence-only data } \\
\text { - Model complexity: MaxEnt models were built with linear and quadratic } \\
\text { features only, to reduce the risk of the model overfitting. } \\
\text { - Model averaging: Model averaging of } 10 \text { replicates. }\end{array}$ \\
\hline Model workflow & $\begin{array}{l}\text { For each of the target species, we developed a MaxEnt model for predicting the } \\
\text { distribution probability by iteratively using the prepared possible combinations of } \\
\text { explanatory variables without multicollinearity issues (See Multicollinearity } \\
\text { section for the details). To select the most parsimonious combination of } \\
\text { explanatory variables, corrected Akaike information criterion (AICc) values were } \\
\text { compared among the candidate models, and the model with the minimum value } \\
\text { was selected }{ }^{17} \text {. Then, we performed parameter tuning for the regularization } \\
\text { parameter (beta) in MaxEnt models based on AICc. We tested } ß \text { values from } 0 \text { to } \\
15 \text { (in increments of } 0.5 \text { ). }\end{array}$ \\
\hline
\end{tabular}




\begin{tabular}{|c|c|}
\hline Software & $\begin{array}{l}\text { - Software: Analyses were conducted in R ver. } 3.3 .2 \text { and R packages rgdal } \\
\text { 1.2-6, raster 2.5-8, rJava 0.9-8, dismo } 1.1-4 \text {, and ENMeval 0.2.2, usdm } \\
\text { 1.1-15, and MaxEnt v3.3 (http://www. Cs.princeton.edu/schapire/maxent/). } \\
\text { Data availability: Available from the corresponding author upon reasonable } \\
\text { request. }\end{array}$ \\
\hline \multicolumn{2}{|l|}{ Data } \\
\hline Biodiversity data & 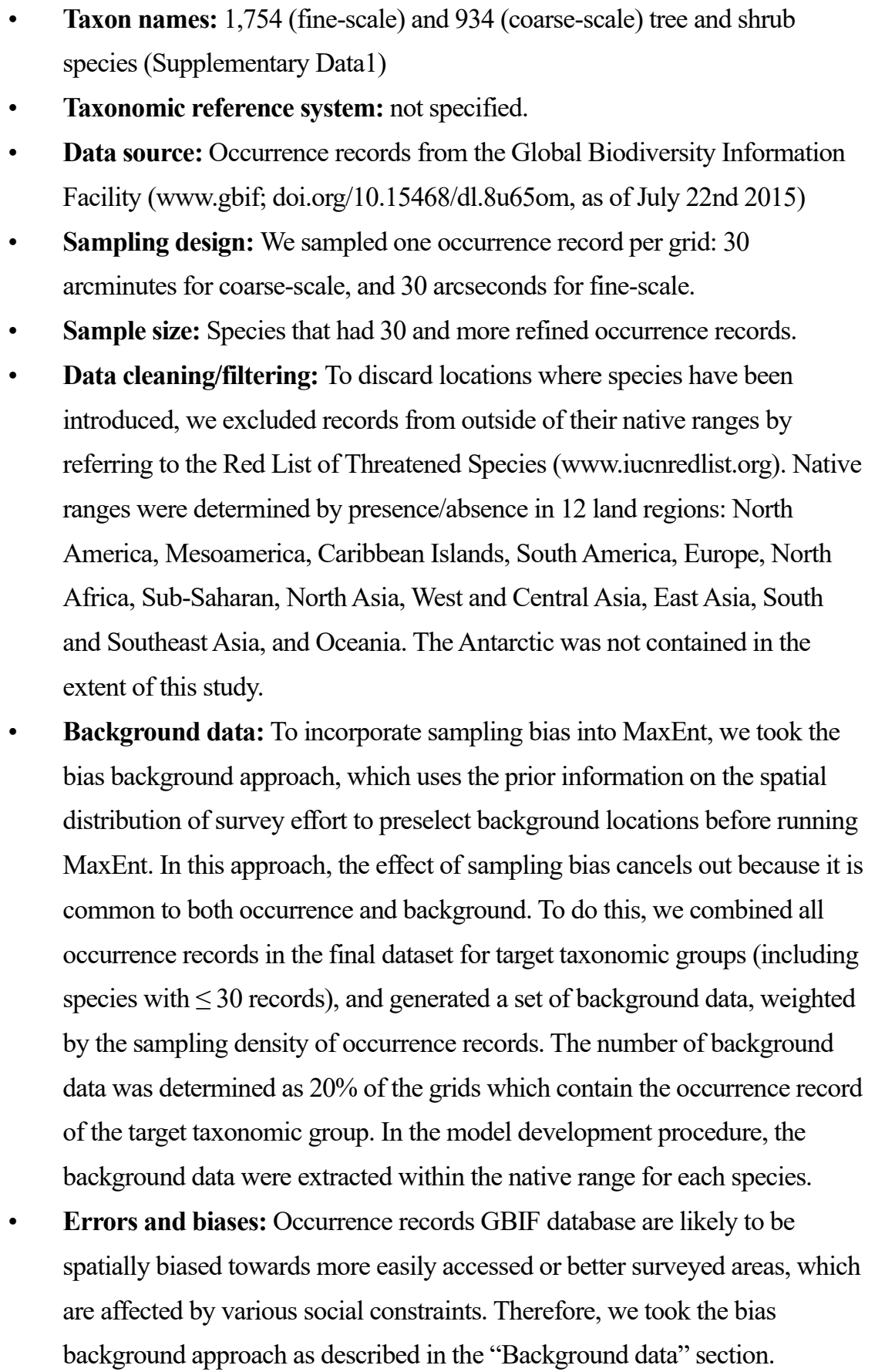 \\
\hline
\end{tabular}




\begin{tabular}{|c|c|}
\hline Data partitioning & The model performance was assessed using 10-fold cross-validation. \\
\hline Predictor variables & $\begin{array}{l}\text { Predictor variables: } \\
\text { Climate: We used } 19 \text { climatic variables from the WorldClim } 1.4 \\
\text { (http://worldclim.com/version1). } \\
\text { BIO1 = Annual Mean Temperature } \\
\text { BIO2 = Mean Diurnal Range (Mean of monthly (max temp - min temp)) } \\
\text { BIO3 = Isothermality (BIO2/BIO7) }\left({ }^{*} 100\right) \\
\text { BIO4 = Temperature Seasonality (standard deviation *100) } \\
\text { BIO5 = Max Temperature of Warmest Month } \\
\text { BIO6 = Min Temperature of Coldest Month } \\
\text { BIO7 = Temperature Annual Range (BIO5-BIO6) } \\
\text { BIO8 = Mean Temperature of Wettest Quarter } \\
\text { BIO9 = Mean Temperature of Driest Quarter } \\
\text { BIO10 = Mean Temperature of Warmest Quarter } \\
\text { BIO11 = Mean Temperature of Coldest Quarter } \\
\text { BIO12 = Annual Precipitation } \\
\text { BIO13 = Precipitation of Wettest Month } \\
\text { BIO14 = Precipitation of Driest Month } \\
\text { BIO15 = Precipitation Seasonality (Coefficient of Variation) } \\
\text { BIO16 = Precipitation of Wettest Quarter } \\
\text { BIO17 = Precipitation of Driest Quarter } \\
\text { BIO18 = Precipitation of Warmest Quarter } \\
\text { BIO19 = Precipitation of Coldest Quarter } \\
\text { Land-use: } \\
\text { [Fine-scale]: MODIS Land Cover Type for the year of } 2005 \\
\left.\text { (glcf.umd.edu/data/lc; as of February } 19^{\text {th }}, 2018\right) \\
\text { [Coarse-scale]: Proportion of each of the five land-use types (cropland, } \\
\text { pasture, forest, other natural lands, and settled land) based on } \\
\text { AIM/PLUM output for } 2005^{10} . \\
\text { Climate: For fine-scale, downloaded 30 arcsecond data was used } \\
\text { directly. For coarse-scale, a dataset of monthly minimum temperature, } \\
\text { maximum temperature, and precipitation was downloaded from the } \\
\text { WorldClim. The dataset at a resolution of } 30 \text { arcseconds was averaged } \\
\text { to values at a resolution of } 30 \text { arcminutes. Then, we calculated } 19 \\
\text { bioclimatic variables based on the three climatic variables, and these } \\
\text { bioclimatic variables were used for the model construction. }\end{array}$ \\
\hline
\end{tabular}




\begin{tabular}{|c|c|c|}
\hline & $\begin{array}{ll} & \text { - } \\
\text { - } & \mathbf{T e} \\
\text { - } & \mathbf{D a} \\
& \text { "a } \\
\mathrm{pa}\end{array}$ & 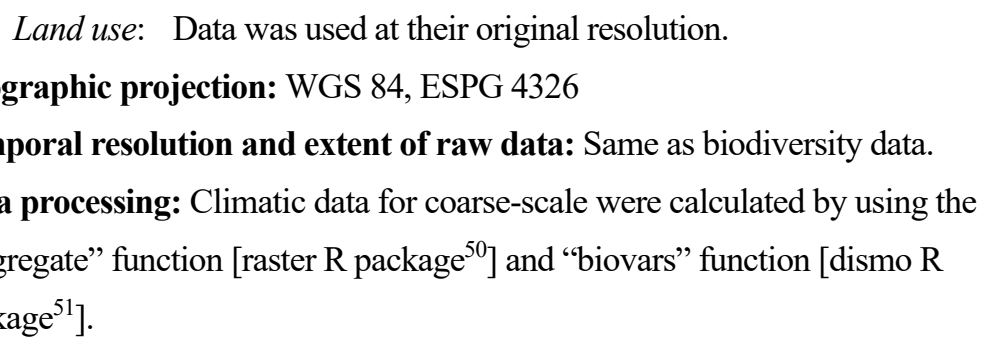 \\
\hline Transfer data for projection & - $\mathbf{M}$ & 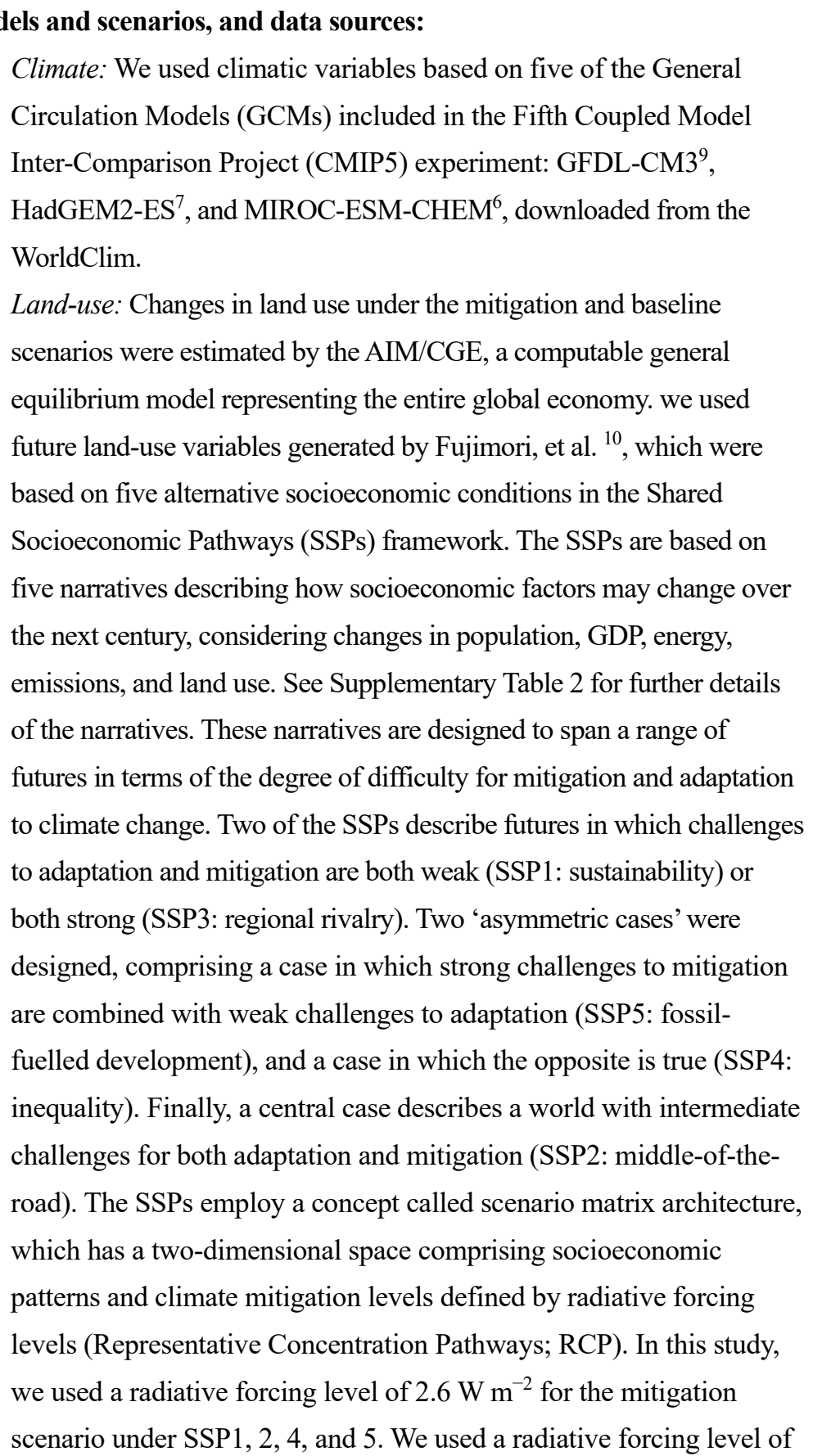 \\
\hline
\end{tabular}




\begin{tabular}{|c|c|}
\hline & $\begin{array}{l}3.4 \mathrm{~W} \mathrm{~m}^{-2} \text { for the mitigation scenario under SSP3, because there was } \\
\text { no solution for } 2.6 \mathrm{~W} \mathrm{~m}^{-2} \text { in SSP3. For the baseline scenario, we used } \\
\text { the baseline condition in each SSP corresponding to a radiative } \\
\text { forcing level of } 8.5 \mathrm{~W} \mathrm{~m}^{-2} \text {, which represents the absence of additional } \\
\text { climate policy. } \\
\text { - Spatial extent and resolution: Same as the coarse-scale model. } \\
\text { Temporal extent/time period: } 2050 \mathrm{~s} \text { and } 2070 \text { s. For climatic data, we used } \\
\text { the average of } 2041-2060 \text { for the } 2050 \mathrm{~s} \text { and the average of } 2061-2080 \text { for } \\
\text { 2070s. }\end{array}$ \\
\hline \multicolumn{2}{|l|}{ Model } \\
\hline Multicollinearity & $\begin{array}{l}\text { First, by using the five land-use and } 19 \text { bioclimatic variables, we generated all } \\
\text { the possible combinations }\left(2^{24}=16,777,216\right) \text { of these variables. We then } \\
\text { excluded explanatory variables showing collinearity: (1) we excluded the set of } \\
\text { explanatory variables that include pairs of highly correlated variables (Pearson's } \\
\text { product moment correlation coefficient } \geq|0.70|) \text {, and }(2) \text { we excluded those } \\
\text { explanatory variables for which the variance inflation factor value, which } \\
\text { indicates the degree of collinearity between two or more predictor variables, } \\
\text { was } \geq 5 \text {. }\end{array}$ \\
\hline Model settings & $\begin{array}{l}\text { - Model settings: We conducted parameter tuning for regularization } \\
\text { parameters as we described in the "Model workflow" section. We restricted } \\
\text { the features into two types (linear and quadratic) as described in the "SDM } \\
\text { algorithms" section. We used default settings for other parameters in MaxEnt. } \\
\text { Model settings for extrapolation: Predictions bounded by clamping in } \\
\text { MaxEnt. }\end{array}$ \\
\hline Model estimates & $\begin{array}{l}\text { - Uncertainty in model coefficients: Cross-validation was used to yield } \\
\text { robust predictions. }\end{array}$ \\
\hline $\begin{array}{l}\text { Model averaging/ } \\
\text { Ensembles }\end{array}$ & We calculated the mean probability of occurrence from 10 replicates. \\
\hline $\begin{array}{l}\text { Non-independence } \\
\text { correction/analyses }\end{array}$ & None \\
\hline Threshold selection & $\begin{array}{l}\text { We used an average of the } 90 \% \text { sensitivity threshold to minimize the false- } \\
\text { negative fractions and to avoid underestimating the suitable habitat area. }\end{array}$ \\
\hline \multicolumn{2}{|l|}{ Assessment } \\
\hline Performance statistics & $\begin{array}{l}\text { We used the continuous Boyce index }(\mathrm{CBI})^{20} \text { calculated on } 10 \text {-fold cross- } \\
\text { validation, to evaluate model quality for predictions based on presence-only data. } \\
\text { This index varies between }-1 \text { and } 1 \text {; negative values indicate an incorrect model, } \\
\text { values close to } 0 \text { mean a chance model, and positive values indicate a model }\end{array}$ \\
\hline
\end{tabular}




\begin{tabular}{|c|c|c|}
\hline & \multicolumn{2}{|c|}{$\begin{array}{l}\text { whose predictions are consistent with the presence distribution in the test set. We } \\
\text { used models with } \mathrm{CBI}>0 \text { based on the } 95 \% \text { confidence interval for the } \\
\text { subsequent analyses. }\end{array}$} \\
\hline Plausibility check & \multicolumn{2}{|l|}{ None } \\
\hline \multicolumn{3}{|l|}{ Prediction } \\
\hline tion output & \multicolumn{2}{|c|}{$\begin{array}{l}\text { - Prediction unit: Predictions bounded by clamping in MaxEnt. } \\
\text { The probability of occurrence was converted into the binary map by using } \\
\text { the threshold (see section Threshold selection), then we calculated the area of } \\
\text { potentially suitable habitat. } \\
\text { Post-processing: } \\
\text { Current: Predicted suitable habitats may appear beyond the species' } \\
\text { native ranges. For each species, we discarded projected suitable habitats } \\
\text { if (1) they were beyond the current native regions recorded in the IUCN } \\
\text { species database, or (2) if they are on a landmass that has not been } \\
\text { connected to other landmasses with occurrence points since the last } \\
\text { glacial maximum period. In this case, the threshold value for the paleo- } \\
\text { coastline was set to -130 m below the current coastline, estimated by } \\
\text { using seafloor topography data (ETOPO1). Although a few exceptional } \\
\text { species with high dispersal ability may have the potential to go beyond } \\
\text { their native range, to evaluate suitable habitat, we made rather } \\
\text { conservative assumptions to minimize commission errors (i.e., } \\
\text { identification of suitable habitats in areas where a given species has } \\
\text { never occurred owing to barriers or other biogeographic limitations). } \\
\text { Future: To identify potential future habitats constrained by dispersal } \\
\text { distance, the estimated dispersal distance for each species was buffered. } \\
\text { Dispersal distance per generation was estimated from the formula based } \\
\text { on Tamme, et al. }{ }^{23} \text {. We adopted the group } 5 \text { formula in the } \\
\text { based on Marba, et al. }{ }^{24} \text {, according to a growth form. }\end{array}$} \\
\hline Uncertainty quantification & $\begin{array}{l}\text { - } \\
\text { D } \\
\text { re } \\
\text { an } \\
\text { ch } \\
\text { co } \\
\text { U }\end{array}$ & $\begin{array}{l}\text { rtainty in estimation of species-specific dispersal distance: } \\
\text { quilibrium between climate change and species dispersal is often } \\
\text { ted }^{52} \text {; generally limited dispersal ability of trees as a sessile organism } \\
\text { labitat fragmentation make it difficult for species to track climate } \\
\text { ge. Also, events such as an exceptional long dispersal }{ }^{53} \text { were not } \\
\text { dered in this study. } \\
\text { rtainty in scenarios: We used the three GCMs for each of the two RCP }\end{array}$ \\
\hline
\end{tabular}


scenarios under each of the SSPs, all of which are based on many assumptions and thus susceptible to uncertainty. 
Supplementary Table 2. Narratives of the Shared Socioeconomic Pathways (SSP). See Riahi, et al. ${ }^{13}$ for further details.

SSP1 Sustainability - Taking the Green Road (Low challenges to mitigation and adaptation): The world shifts gradually, but pervasively, toward a more sustainable path, emphasizing more inclusive development that respects perceived environmental boundaries. Management of the global commons slowly improves, educational and health investments accelerate the demographic transition, and the emphasis on economic growth shifts toward a broader emphasis on human well-being. Driven by an increasing commitment to achieving development goals, inequality is reduced both across and within countries. Consumption is oriented toward low material growth and lower resource and energy intensity.

SSP2 Middle of the Road (Medium challenges to mitigation and adaptation): The world follows a path in which social, economic, and technological trends do not shift markedly from historical patterns. Development and income growth proceeds unevenly, with some countries making relatively good progress while others fall short of expectations. Global and national institutions work toward but make slow progress in achieving sustainable development goals. Environmental systems experience degradation, although there are some improvements and overall, the intensity of resource and energy use declines. Global population growth is moderate and levels off in the second half of the century. Income inequality persists or improves only slowly and challenges to reducing vulnerability to societal and environmental changes remain.

SSP3 Regional Rivalry - A Rocky Road (High challenges to mitigation and adaptation): A resurgent nationalism, concerns about competitiveness and security, and regional conflicts push countries to increasingly focus on domestic or, at most, regional issues. Policies shift over time to become increasingly oriented toward national and regional security issues. Countries focus on achieving energy and food security goals within their own regions at the expense of broader-based development. Investments in education and technological development decline. Economic development is slow, consumption is material-intensive, and inequalities persist or worsen over time. Population growth is low in industrialized and high in developing countries. A low international priority for addressing environmental concerns leads to strong environmental degradation in some regions.

SSP4 Inequality - A Road Divided (Low challenges to mitigation, high challenges to adaptation): Highly unequal investments in human capital, combined with increasing disparities in economic opportunity and political power, lead to increasing inequalities and stratification both across and within countries. Over time, a gap widens between an internationally connected society that contributes to knowledge- and capitalintensive sectors of the global economy, and a fragmented collection of lower-income, poorly educated societies that work in a labor intensive, low-tech economy. Social cohesion degrades and conflict and unrest become increasingly common. Technology development is high in the high-tech economy and sectors. The globally connected energy sector diversifies, with investments in both carbon-intensive fuels like coal and 
unconventional oil, but also low-carbon energy sources. Environmental policies focus on local issues around middle- and high-income areas.

SSP5 Fossil-fueled Development - Taking the Highway (High challenges to mitigation, low challenges to adaptation): This world places increasing faith in competitive markets, innovation and participatory societies to produce rapid technological progress and development of human capital as the path to sustainable development. Global markets are increasingly integrated. There are also strong investments in health, education, and institutions to enhance human and social capital. At the same time, the push for economic and social development is coupled with the exploitation of abundant fossil fuel resources and the adoption of resource and energy intensive lifestyles around the world. All these factors lead to rapid growth of the global economy, while global population peaks and declines in the 21 st century. Local environmental problems like air pollution are successfully managed. There is faith in the ability to effectively manage social and ecological systems, including by geo-engineering if necessary. 
1. Species distribution modelling ${ }^{4}$ based on climatic ${ }^{55}$ and land-use variables ${ }^{7,53,54}$

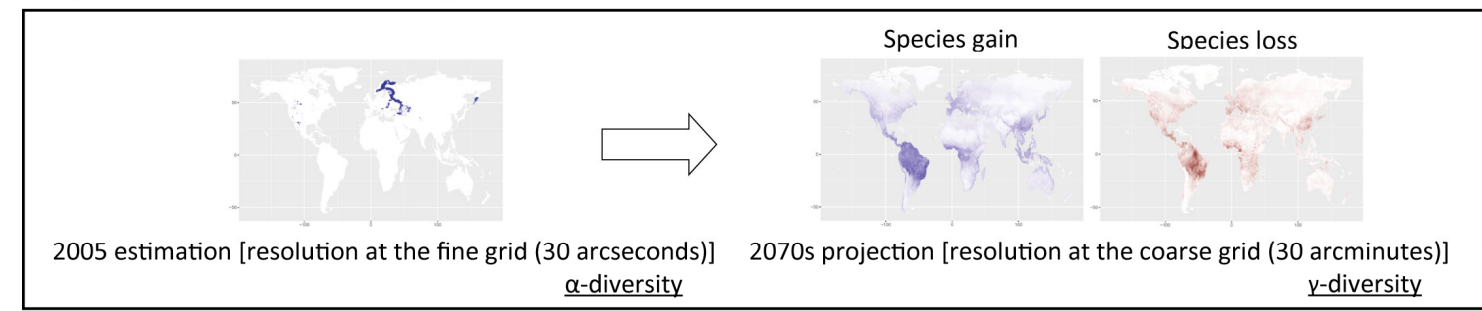

\section{Downscaling (see Figure S2 for the details)}

Because of the difference in spatial resolution between the two periods (constrained by the land-use projections), future projections were only possible at the scale of coarse grids ( $\nu$-diversity). Thus, future projections for $\nu$-diversity in each coarse grid were downscaled into the scale of fine grids ( $\alpha$-diversity). Another constraint was that, because of the requirement for species to have at least 30 occurrences $^{4}$, the future projections using species distribution modelling were only possible for widespread common species.

\section{2-1. Simulations}

Two spatially explicit simulations were conducted in 25,000 artificial landscapes for species co-extinction and co-immigration, respectively. In the simulated landscapes, many possible combinations of species-abundance distributions, species pool size, and total abundance of trees were considered. Based on the results of these simulations, machine learning regressions were constructed to know how many habitats at the scale of fine grids were required for losing or gaining narrow-ranging rare species following extinction or immigration of common species, respectively.

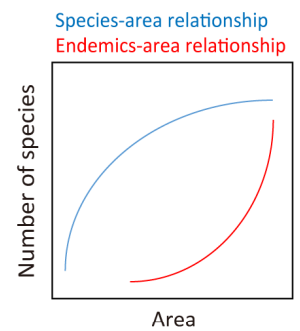

\section{2-2. Downscaling}

Machine learning regressions were used to estimate possible $\gamma$-diversity by extracting the number of extinct widespread and co-extinct rare species and by adding the number of immigrated widespread and co-immigrated rare species from $\gamma$-diversity in 2005. Total species extinction and immigration within each of coarse grids by 2070 s were downscaled into the fine-scale to estimate $\alpha$-diversity, using endemics-area relationship and species-area relationship unique to individual coarse grids.

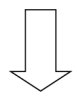

\section{Proportional changes in $\alpha$-diversity}

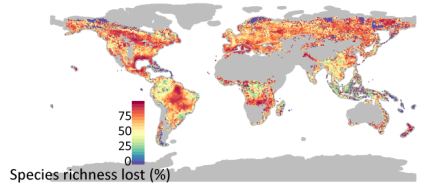

2070 s projection [resolution at the fine grid (30 arcseconds)]

\section{Productivity estimation}

Proportional changes in species richness within each of the fine grids were converted into proportional changes in productivity in these localities using the known equation ${ }^{21}$ and these estimates were multiplied by remote sensing estimations for net primary productivity ${ }^{34}$ to know absolute changes in productivity.
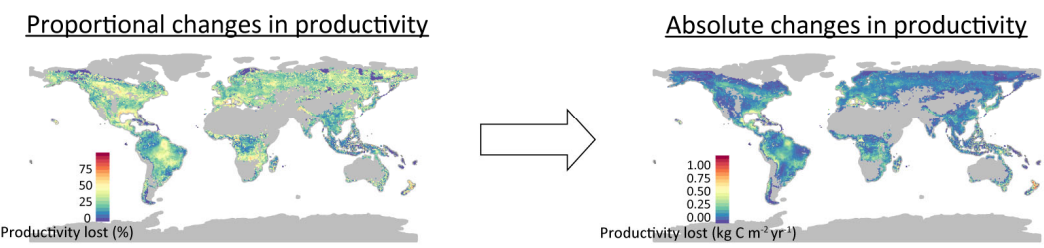

2070s projection [resolution at the fine grid (30 arcseconds)]

The above procedures were repeated for two representative concentration pathways (baseline and mitigation scenario) for each of five shared socioeconomic pathways (SSPs) in three global climate models (GCMs). 
Supplementary Figure 1. Overall workflow to estimate changes in species richness and productivity by 2070 s. 


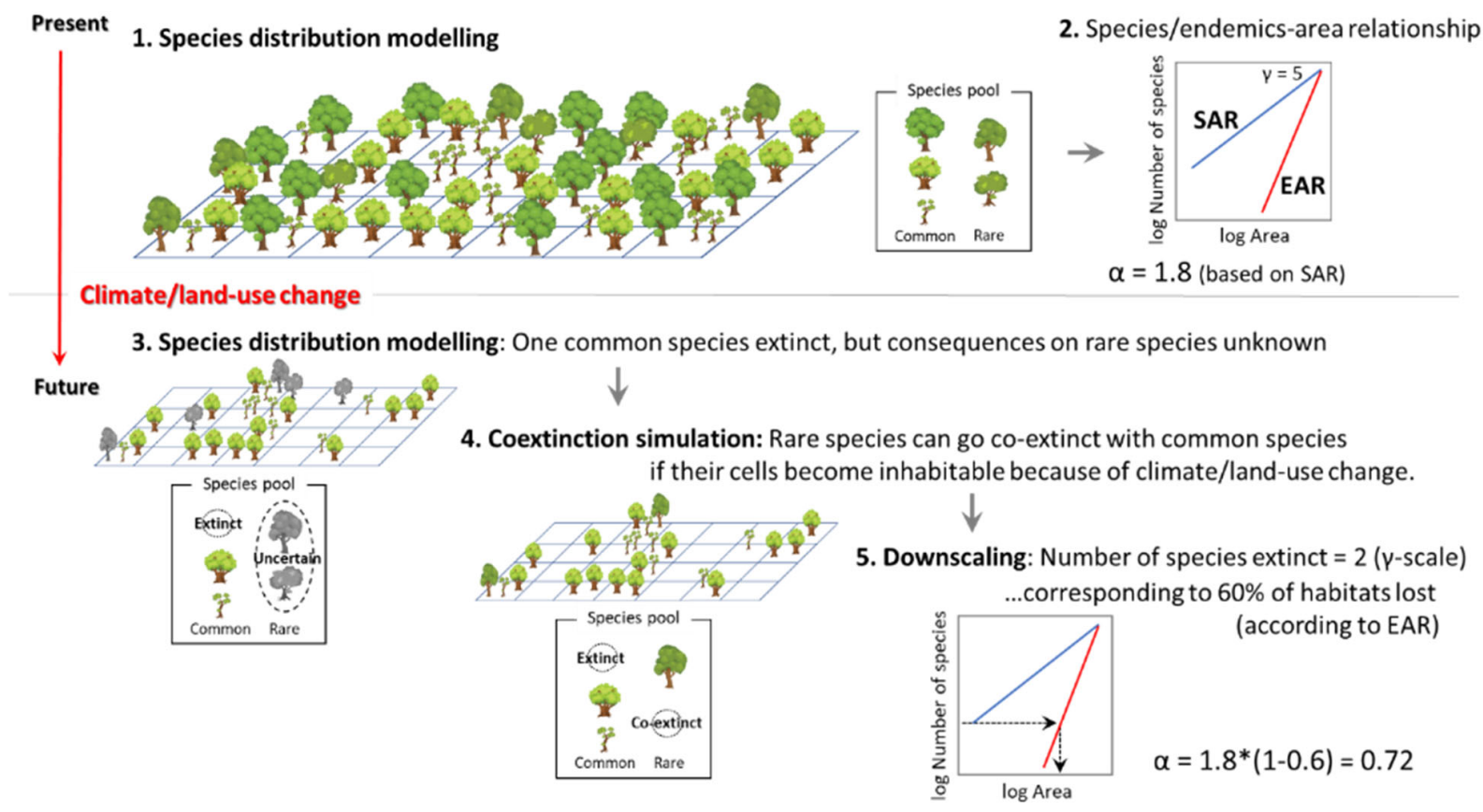

Supplementary Figure 2. Schematic diagram to downscale changes in species richness from $\gamma$-scale to $\alpha$-scale. Note that this hypothetical landscape is only to visualize the calculation for the case of species co-extinction. In this hypothetical example, $60 \%$ of habitats must be destroyed to remove 2 species from the landscape (according to the endemic-area relationship; EAR). Thus, $\alpha$-diversity in future was estimated as $1.8 *(1-0.6)=0.72$. For species co-immigration (not visualized), the amount of habitat required to have additional species was estimated based on species-area relationship (SAR). For instance, suppose getting additional species, on average, required $5 \%$ of the above hypothetical landscape and future $\gamma$-diversity was estimated to increase from 5 to $6, \alpha$-diversity in future was calculated as $1.8 *(1+0.05)=1.89$. 


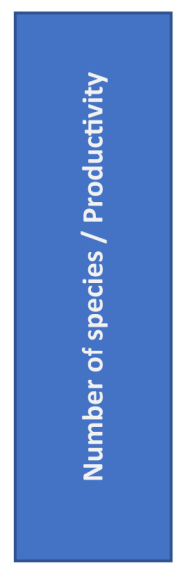

Present

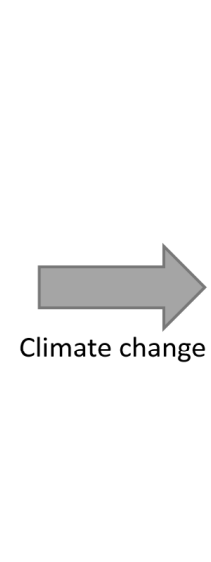

Baseline scenario
Loss

Effectiveness to

alleviate the loss of

species/productivity

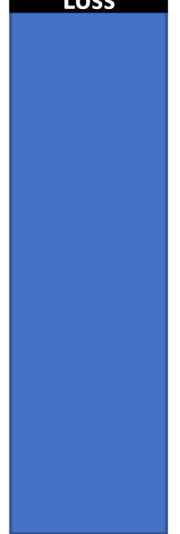

Mitigation scenario

\section{$\underline{\text { Future }}$}

Supplementary Figure 3. Schematic explanation for the effectiveness of climate mitigation efforts to alleviate the impacts of climate change on tree species and the associated productivity in forested biomes. Results from mitigation scenario was compared with those based on baseline scenario, and the double-pointing black arrow is the effectiveness of mitigation efforts. In this example, the effectiveness is positive, which is shown as a positive effect size in Figs. 2, 3 and 5, and Extended Data Figs. 3, 4 and 7. 

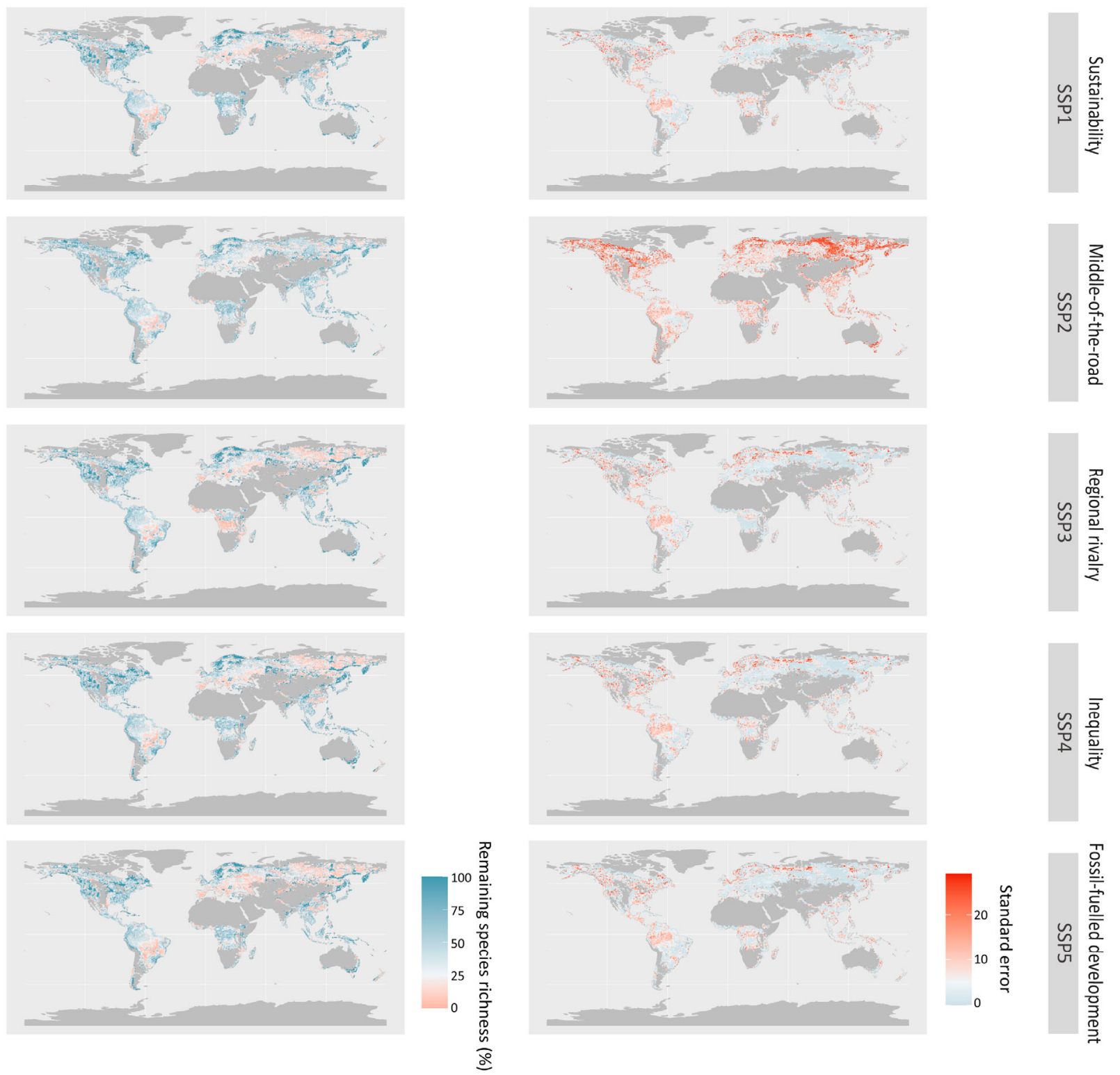

Supplementary Figure 4. Maps showing the projected changes in tree diversity under the mitigation scenarios from 2005 to 2070s. Results are based on means (left column) and standard errors (right column) of proportional changes (\%) in $\alpha$-diversity (remaining species richness estimated at the fine grid-scale) within each of the coarse grids, calculated across the three General Circulation Models (GCMs) ( $n=32,670$ grids). Results are shown for the five Shared Socioeconomic Pathways (SSPs). Results of individual GCMs are shown in Extended Data Figure 1. 

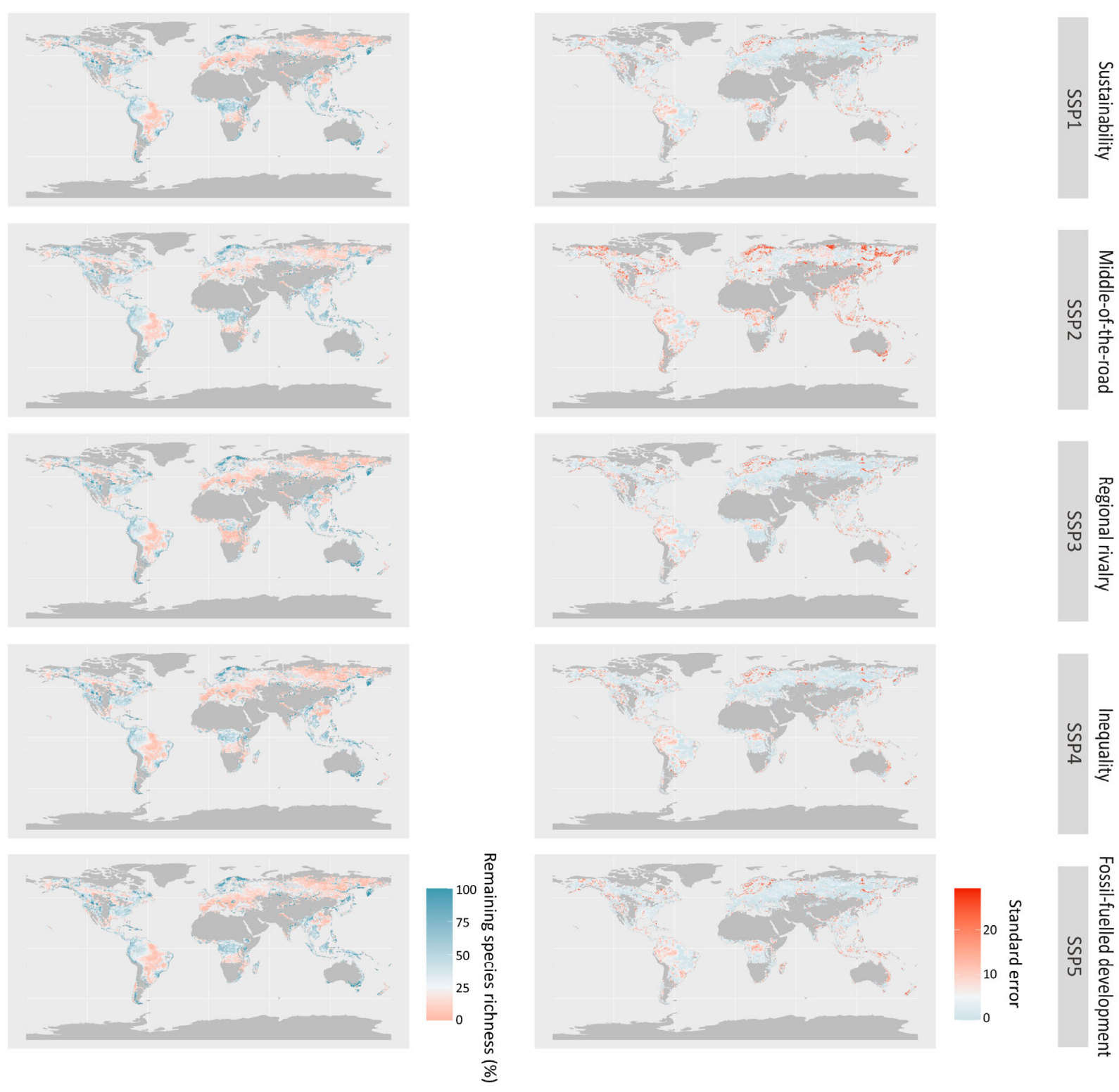

Supplementary Figure 5. Maps showing the projected changes in tree diversity under the baseline scenarios from 2005 to 2070s. Results are based on means (left column) and standard errors (right column) of proportional changes (\%) in $\alpha$-diversity (remaining species richness estimated at the fine grid-scale) within each of the coarse grids from 2005 to 2070s, calculated across the three General Circulation Models (GCMs) ( $\mathrm{n}=32,670$ grids). Results are shown for the five Shared Socioeconomic Pathways (SSPs). Results of individual GCMs are shown in Extended Data Figure 2. 


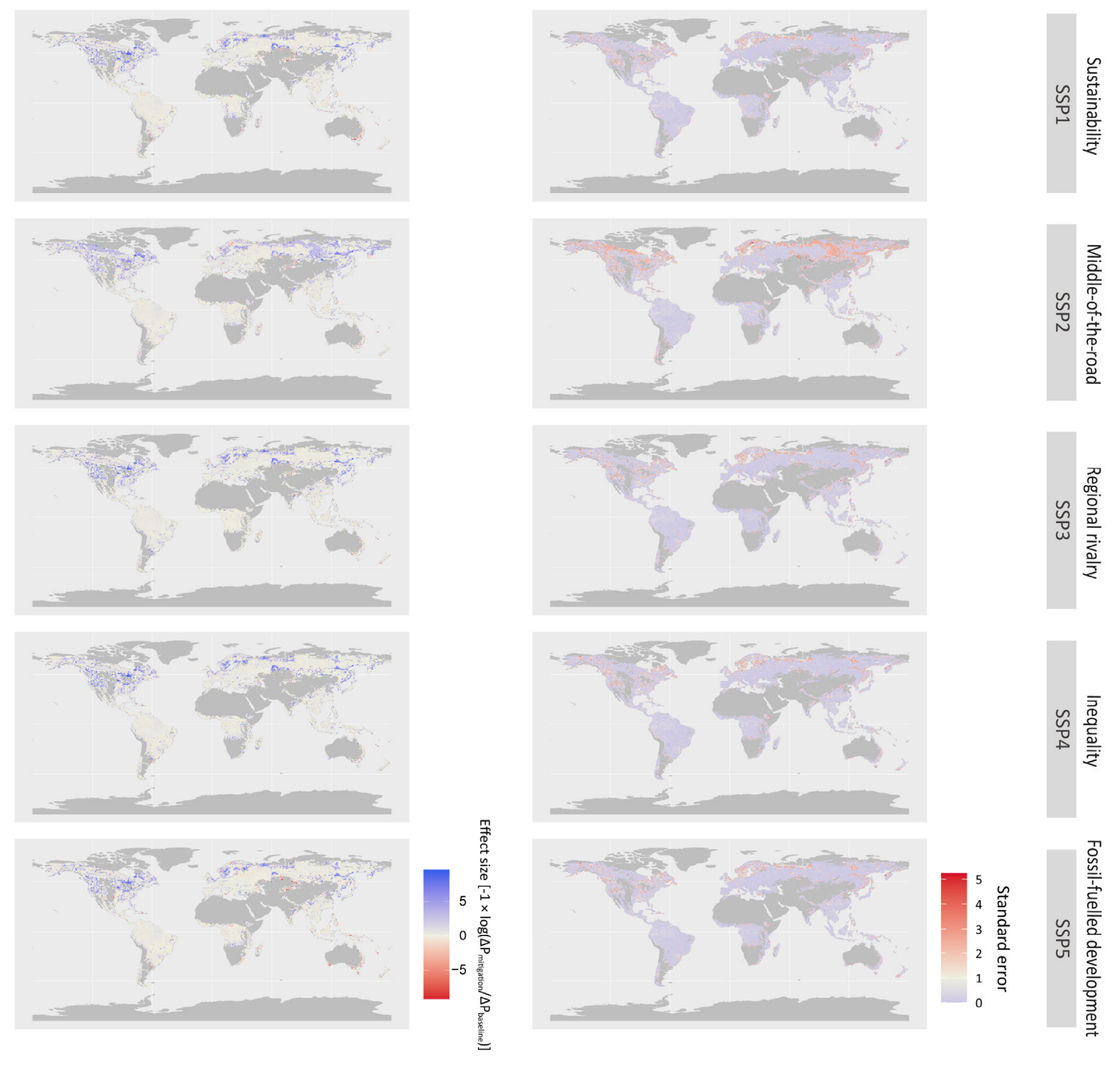

Supplementary Figure 6. Maps showing the effects of a climate change mitigation to alleviate the loss of tree diversity-dependent productivity $(\Delta P)$ from 2005 to 2070s. The effect sizes [inverse of $\log$ (mitigation/baseline)] of $\Delta \mathrm{P}$ are shown for each of the coarse grids, calculated across the three General Circulation Models (GCMs) ( $=32,670$ grids). Results are shown for the five Shared Socioeconomic Pathways (SSPs). Results of individual GCMs are shown in Extended Data Figure 5. 


\section{References}

1 Ohashi, H. et al. Biodiversity can benefit from climate stabilization despite adverse side effects of land-based mitigation. Nat Commun 10, 5240, doi:10.1038/s41467-019-13241-y (2019).

2 Zurell, D. et al. A standard protocol for reporting species distribution models. Ecography 43, 1261-1277, doi:10.1111/ecog.04960 (2020).

3 Warren, R. et al. Quantifying the benefit of early climate change mitigation in avoiding biodiversity loss. Nat Clim Change 3, 678-682, doi:10.1038/nclimate1887 (2013).

4 Wisz, M. S. et al. Effects of sample size on the performance of species distribution models. Divers Distrib 14, 763-773, doi:10.1111/j.1472-4642.2008.00482.x (2008).

5 Hijmans, R. J., Cameron, S. E., Parra, J. L., Jones, P. G. \& Jarvis, A. Very high resolution interpolated climate surfaces for global land areas. Int J Climatol 25, 1965-1978, doi:10.1002/joc.1276 (2005).

6 Watanabe, S. et al. MIROC-ESM 2010: model description and basic results of CMIP5-20c3m experiments. Geoscientific Model Development 4, 845-872, doi:10.5194/gmd-4-845-2011 (2011).

7 Collins, W. J. et al. Development and evaluation of an Earth-System model - HadGEM2. Geoscientific Model Development 4, 1051-1075, doi:10.5194/gmd-4-1051-2011 (2011).

8 Jones, C. D. et al. The HadGEM2-ES implementation of CMIP5 centennial simulations. Geoscientific Model Development 4, 543-570, doi:10.5194/gmd-4-543-2011 (2011).

9 Griffies, S. M. et al. The GFDL CM3 Coupled Climate Model: Characteristics of the Ocean and Sea Ice Simulations. Journal of Climate 24, 3520-3544, doi:10.1175/2011jcli3964.1 (2011).

10 Fujimori, S., Hasegawa, T., Ito, A., Takahashi, K. \& Masui, T. Gridded emissions and landuse data for 2005-2100 under diverse socioeconomic and climate mitigation scenarios. Scientific Data 5, 180210, doi:10.1038/sdata.2018.210 (2018).

11 Fujimori, S., Hasegawa, T. \& Masui, T. AIM/CGE V2.0: Basic Feature of the Model. (Springer Nature Singapore, 2017).

12 Hasegawa, T., Fujimori, S., Ito, A., Takahashi, K. \& Masui, T. Global land-use allocation model linked to an integrated assessment model. Science of the Total Environment 580, 787796, doi:10.1016/j.scitotenv.2016.12.025 (2017).

13 Riahi, K. et al. The Shared Socioeconomic Pathways and their energy, land use, and greenhouse gas emissions implications: An overview. Global Environmental Change 42, 153168, doi:10.1016/j.gloenvcha.2016.05.009 (2017).

14 Fujimori, S. et al. SSP3: AIM implementation of Shared Socioeconomic Pathways. Global Environmental Change 42, 268-283, doi:10.1016/j.gloenvcha.2016.06.009 (2017).

15 Phillips, S. J., Anderson, R. P. \& Schapire, R. E. Maximum entropy modeling of species 
geographic distributions. Ecol Model 190, 231-259, doi:10.1016/j.ecolmodel.2005.03.026 (2006).

16 Elith, J., Kearney, M. \& Phillips, S. The art of modelling range-shifting species. Method Ecol Evol 1, 330-342, doi:10.1111/j.2041-210X.2010.00036.x (2010).

17 Warren, D. L. \& Seifert, S. N. Ecological niche modeling in Maxent: the importance of model complexity and the performance of model selection criteria. Ecol Appl 21, 335-342, doi:10.1890/10-1171.1 (2011).

18 Merow, C., Smith, M. J. \& Silander, J. A. A practical guide to MaxEnt for modeling species' distributions: what it does, and why inputs and settings matter. Ecography 36, 1058-1069, doi:10.1111/j.1600-0587.2013.07872.x (2013).

19 Warren, D. L., Wright, A. N., Seifert, S. N., Shaffer, H. B. \& Franklin, J. Incorporating model complexity and spatial sampling bias into ecological niche models of climate change risks faced by 90 California vertebrate species of concern. Divers Distrib 20, 334-343, doi:10.1111/ddi.12160 (2014).

20 Boyce, M. S., Vernier, P. R., Nielsen, S. E. \& Schmiegelow, F. K. A. Evaluating resource selection functions. Ecol Model 157, 281-300, doi:10.1016/s0304-3800(02)00200-4 (2002).

21 Pearson, R. G., Dawson, T. P. \& Liu, C. Modelling species distributions in Britain: a hierarchical integration of climate and land-cover data. Ecography 27, 285-298, doi:10.1111/j.0906-7590.2004.03740.x (2004).

22 Bullock, J. M. et al. Modelling spread of British wind-dispersed plants under future wind speeds in a changing climate. $J$ Ecol 100, 104-115, doi:10.1111/j.1365-2745.2011.01910.x (2012).

23 Tamme, R. et al. Predicting species' maximum dispersal distances from simple plant traits. Ecology 95, 505-513, doi:10.1890/13-1000.1 (2014).

24 Marba, N., Duarte, C. M. \& Agusti, S. Allometric scaling of plant life history. Proc Natl Acad Sci U S A 104, 15777-15780, doi:10.1073/pnas.0703476104 (2007).

25 Community Ecology Package 'vegan' version 2.5-4 (2019).

26 May, F., Gerstner, K., McGlinn, D. J., Xiao, X. \& Chase, J. M. mobsim: An R package for the simulation and measurement of biodiversity across spatial scales. Method Ecol Evol, doi:10.1111/2041-210x.12986 (2018).

27 Chen, T. \& Guestrin, C. in Tthe 22nd ACM SIGKDD International Conference on Knowledge Discovery and Data Mining. 785-794.

28 R: A language and environment for statistical computing. R Foundation for Statistical Computing (Vienna, Austria, 2017).

29 Chase, J. M. \& Leibold, M. A. Spatial scale dictates the productivity-biodiversity relationship. Nature 416, 427-430, doi:10.1038/416427a (2002).

30 Gonzalez, A. et al. Scaling-up biodiversity-ecosystem functioning research. Ecol Lett 23, 757- 
776, doi:10.1111/ele.13456 (2020).

31 Liang, J. et al. Positive biodiversity-productivity relationship predominant in global forests. Science 354, doi:10.1126/science.aaf8957 (2016).

32 Colwell, R. K., Dunn, R. R. \& Harris, N. C. Coextinction and persistence of dependent species in a changing world. Ann Rev Ecol Evol Syst 43, 183-203, doi:10.1146/annurev-ecolsys110411-160304 (2012).

33 Koh, L. P. et al. Species coextinctions and the biodiversity crisis. Science 305, 1632-1634 (2004).

34 Engen, S., Lande, R., Walla, T. \& DeVries, P. J. Analyzing spatial structure of communities using the two-dimensional poisson lognormal species abundance model. The American Naturalist 160, 60-73, doi:10.1086/340612 (2002).

35 He, F. \& Gaston, K. J. Occupancy, spatial variance, and the abundance of species. The American Naturalist 162, 366-375, doi:10.1086/377190 (2003).

36 Magurran, A. E. \& McGill, B. J. Biological diversity. (Oxford University Press, 2011).

37 Whittaker, R. H. Vegetation of the Siskiyou Mountains, Oregon and California. Ecological Monographs 30, 279-338 (1960).

38 Mori, A. S. et al. Functional redundancy of multiple forest taxa along an elevational gradient: predicting the consequences of non-random species loss. J Biogeogr 42, 1383-1396, doi:10.1111/jbi.12514 (2015).

39 Stürck, J. et al. Simulating and delineating future land change trajectories across Europe. Regional Environmental Change 18, 733-749, doi:10.1007/s10113-015-0876-0 (2015).

40 He, F. \& Hubbell, S. P. Species-area relationships always overestimate extinction rates from habitat loss. Nature 473, 368-371, doi:10.1038/nature09985 (2011).

41 Neigel, J. E. Species-area relationships and marine conservation. Ecol Appl 13, 138-145, doi:10.1890/1051-0761(2003)013[0138:saramc]2.0.co;2 (2003).

42 Rogan, J. E. \& Lacher, T. E. Impacts of Habitat Loss and Fragmentation on Terrestrial Biodiversity. doi:10.1016/b978-0-12-409548-9.10913-3 (2018).

Running, S., Mu, Q., Zhao, M. \& MODAPS-SIPS.

(NASA, 2015).

44 maptools: Tools for Reading and Handling Spatial Objects. R package version 0.9-2 (2017).

45 sf: Simple Features for R. R package version 0.6-3 (2018).

46 Wickham, H. et al. Welcome to the Tidyverse. Journal of Open Source Software 4, doi:10.21105/joss.01686 (2019).

47 ARPobservation: Simulating recording procedures for direct observation of behavior. R package version 1.1 (2018).

48 Viechtbauer, W. Conducting Meta-Analyses in R with the metafor Package. Journal of Statistical Software 36, doi:10.18637/jss.v036.i03 (2010).

49 Ricke, K., Drouet, L., Caldeira, K. \& Tavoni, M. Country-level social cost of carbon. Nat 
Clim Change 8, 895-900, doi:10.1038/s41558-018-0282-y (2018).

50 raster: Geographic Data Analysis and Modeling v. R package version 3.0-12 (2020).

51 dismo: Species Distribution Modeling (2017).

52 Fadrique, B. et al. Widespread but heterogeneous responses of Andean forests to climate change. Nature 564, 207-212, doi:10.1038/s41586-018-0715-9 (2018).

53 Jordano, P. \& Rees, M. What is long-distance dispersal? And a taxonomy of dispersal events. $J$ Ecol 105, 75-84, doi:10.1111/1365-2745.12690 (2017).

54 BGCI. Global Tree Search Database (Botanic Gardens Conservation International, 2019). 